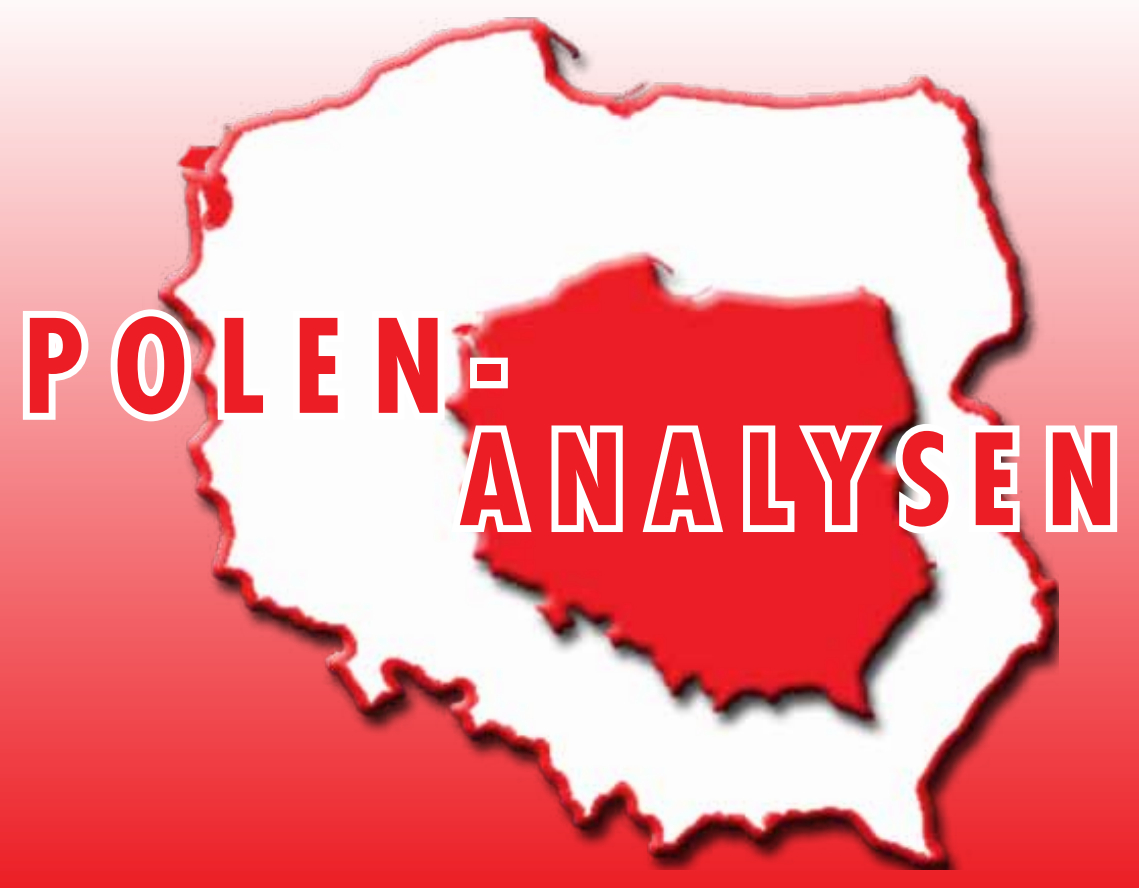

www.laender-analysen.de/polen

\title{
EINWANDERUNGSPOLITIK
}

ANALYSE

Einwanderungspolitik in einem Auswandererland

Anna Kicinger, Warschau

- TABELLEN UND GRAFIKEN

Statistiken zu Visa, Niederlassungserlaubnis und Flüchtlingen in Polen

CHRONIK

Vom 19. Januar bis zum 01. Februar 2010

LESEHINWEIS

Jahrbuch Polen 2010 Migration 


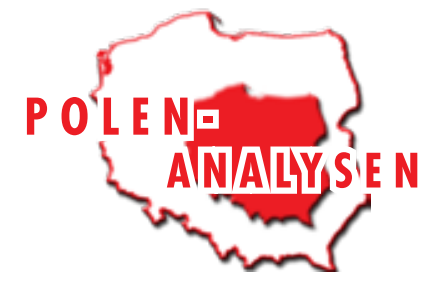

Analyse

\section{Einwanderungspolitik in einem Auswandererland}

Anna Kicinger, Warschau

\section{Zusammenfassung}

Nach den Massenumsiedlungen der Nachkriegszeit entwickelte sich Polen unter kommunistischer Herrschaft zu einem Land, in dem die Auswanderung von oben her beschränkt wurde und eine Einwanderung praktisch nicht stattfand. Aus politischen und wirtschaftlichen Gründen stand Polen vor 1989 abseits der Wege, die Asylsuchende einschlugen. Der Umbruch im Jahre 1989 und die anschließende politische und wirtschaftliche Transformation in Polen sowie in den übrigen Ländern Ostmittel- und Osteuropas führten zu einer wesentlichen Veränderung des Bildes der Wanderungsbewegungen in Polen. Zwar bleibt die Emigration um ein vielfaches höher als die Immigration, doch kommen nun Ausländer aus verschiedenen Ländern und mit unterschiedlichem Rechtsstatus nach Polen, legal und illegal. Polen ist für sie entweder Durchgangsland auf dem Weg nach Westen oder, immer öfter, Ziel ihrer Migration. Die Autorin stellt die unterschiedlichen Beweggründe für die Einwanderung nach Polen und die Lebenssituation der Immigranten dar und skizziert die aktuelle Ausländerpolitik

$\mathrm{N}$ ach den Massenumsiedlungen der Nachkriegszeit entwickelte sich Polen unter kommunistischer Herrschaft zu einem Land, in dem die Auswanderung von oben her beschränkt wurde und eine Einwanderung praktisch nicht stattfand. Unser Wissen über Einwanderungen ist marginal, wie auch die Zahl der Ausländer, die nach Polen kamen, verschwindend gering ist. In den 1960er, 1970er und 1980er Jahren waren durchschnittlich 1.900 Ausländer mit ständigem Aufenthalt in Polen gemeldet ${ }^{1}$. Bei einem so geringen Zustrom, der zum großen Teil (genaue Zahlen liegen nicht vor) aus heimkehrenden Polen bestand, war ein Ausländer in der Volksrepublik Polen eine außergewöhnliche und exotische Erscheinung. Ausländer, noch dazu mit auffälligem Äußeren, waren damals im Prinzip ausschließlich in den großen Städten anzutreffen, die von ausländischen Touristen besucht wurden und in denen Studenten aus "befreundeten" arabischen, afrikanischen und asiatischen Staaten lebten. Aus politischen und wirtschaftlichen Gründen stand Polen vor 1989 abseits der Wege, die Asylsuchende einschlugen. Außer Kommunisten aus Griechenland und Flüchtlingen aus Chile verirrten sich in den 1980er Jahren nur einige wenige Flüchtlinge - vorübergehend - nach Polen, was nur ein Vorspiel für die spätere Einbindung Polens in die internationale Flüchtlingskonvention war.

Der Umbruch im Jahre 1989 und die anschließende politische und wirtschaftliche Transformation in Polen sowie in den übrigen Ostblockländern veränderte das Bild der Migration in Polen wesentlich. Zwar übertraf

1 Die statistischen Daten dieses Berichts stützen sich auf Angaben des Portals des Amtes für Ausländerangelegenheiten (Urząd do Spraw Cudzoziemców): www.udsc.gov.pl weiterhin die Emigration die Immigration bei Weitem, doch kamen nun Ausländer aus verschiedenen Ländern und mit unterschiedlichem Rechtsstatus nach Polen, legal und illegal. Polen war für sie entweder Durchgangsland auf dem Weg nach Westen oder, immer öfter, Ziel ihrer Reise.

\section{Der kleine Grenzverkehr}

Eine erste wichtige Weichenstellung, die sich als schwerwiegend für die Entwicklung der Zuwanderung nach Polen erwies, war die Entscheidung der polnischen Regierung, den visumsfreien Verkehr mit Angehörigen der Nachfolgestaaten der UdSSR beizubehalten. Ukrainer, Belarussen und Russen kamen, als die Ausreisebeschränkungen für sie entfielen, massenweise nach Polen und entwickelten dort vor allem grenznahen Handel in großem Stil. Unter ihnen waren und bleiben die Ukrainer die größte Gruppe. Die polnische Ostgrenze belebte sich und die Basare und Märkte in den Grenzstädtchen füllten sich mit Händlern aus dem Osten. Obwohl dieser Umsatz hauptsächlich in der Grauzone blieb, beobachtete die Regierung mit Wohlwollen den blühenden Handel und die gleichzeitig intensivierten persönlichen Kontakte. Der polnische Außenminister Andrzej Olechowski nannte 1994 die Präsenz von Händlern aus dem Osten und die allgemeine Akzeptanz in der polnischen Gesellschaft ein »Wunder der Normalität« - nach Jahren künstlicher Abschottung lebten die nachbarschaftlichen Beziehungen vor allem mit der Ukraine auf.

Ab Mitte der 1990er Jahre war der Kleinhandel aufgrund von Wechselkursänderungen und wirtschaftlichen Veränderungen in Polen nicht mehr lukrativ. Die Händler aus dem Osten wurden so zu temporären Arbeitneh- 


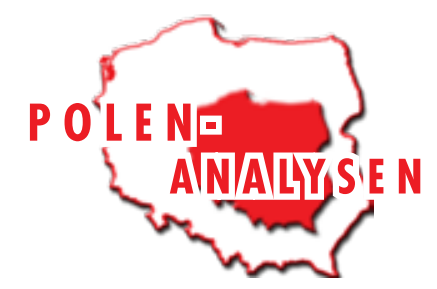

mern, die Arbeiten in der Landwirtschaft, im Obstanbau, im Bauwesen (v. a. Männer) sowie in privaten Haushalten beim Putzen oder bei der Betreuung von Kindern und Pflegebedürftigen (v. a. Frauen) übernahmen. Die Transformation von Händlern zu temporären Arbeitsmigranten vollzog sich, als in Polen trotz offiziell registrierter hoher Arbeitslosigkeit strukturelle Lücken auf dem Arbeitsmarkt auftraten: Es entstand eine Nachfrage nach billigen und flexiblen Arbeitskräften in bestimmten Wirtschaftszweigen. Diese Nische füllten - ähnlich wie in den entwickelten Ländern des Westens - Migranten. Die Ankömmlinge aus dem Osten arbeiteten zumeist illegal und das nicht nur wegen der geringeren Kosten illegaler Arbeit für den Arbeitgeber (und folglich des kurzfristig höheren Einkommens für den Arbeiter), sondern auch wegen des komplizierten, zeitaufwändigen und kostspieligen Systems der Beantragung einer Arbeitserlaubnis.

Der lebhafte Grenzverkehr im Osten wurde für die Gestalter der polnischen Migrationspolitik zu einer Herausforderung. Es entstand ein Spannungsfeld zwischen der zwar unausgesprochenen, inoffiziellen, aber sehr deutlichen Erwartung der westeuropäischen Staaten, dass Polen den Schutz seiner Ostgrenze verstärken und die europäische Staatengemeinschaft vor dem Zustrom aus dem Osten bewahren sollte, und andererseits den Vorteilen, die die Politik der freien Einreise mit sich brachte. Die polnischen Entscheidungsträger waren der Überzeugung, dass diese Politik nicht nur die Gesellschaften einander näherbringe und so der Umsetzung der Ziele in der Außenpolitik - der Annäherung an den Osten - diene, sondern auch wirtschaftlich für Polen einträglich sei.

\section{Händler und Saisonarbeiter}

Die illegalen Arbeitskräfte aus der Ukraine und im kleineren Umfang aus Belarus und Russland wurden zur zahlenmäßig größten Migrantengruppe in Polen. Es gibt keine präzisen Zahlen, wie viele der Ukrainer, die nach Polen einreisten, hier eine Arbeit annahmen; Schätzungen schwanken zwischen 200.000 und 500.000 Arbeitern jährlich. Die Schwarzarbeit wurde zumeist so ausgeübt, dass das Aufenthaltsrecht nicht verletzt wurde. Es wurde also nur im Rahmen der zulässigen Zeit im visumsfreien Verkehr gearbeitet, ab 2003 drei Monate innerhalb eines halben Jahres im Rahmen eines gültigen Visums. Nur ein geringer Teil der Arbeiter aus dem Osten verlängerte seinen Aufenthalt in Polen illegal.

Es handelte sich aber überwiegend um nicht gemeldete Beschäftigungen. Die gemeldete, also legale Beschäftigung von Ausländern in Polen blieb auf sehr niedri- gem Niveau. Das restriktive System zur Erteilung einer Arbeitserlaubnis, das Anfang der 1990er Jahre entstand, sollte vor allem den inländischen Arbeitsmarkt schützen - ein Hauptziel der polnischen Ausländerpolitik. Die Arbeit von Ausländern sollte ausschließlich die Arbeit von Polen ergänzen. Die Arbeitserlaubnis wurde einem Ausländer also nur unter der Bedingung erteilt, dass für die betreffende Stelle kein Pole zur Verfügung stand, und nur für begrenzte Zeit, für eine bestimmte Position und für einen konkreten Arbeitgeber. Das Verfahren, das dem Erhalt einer Arbeitserlaubnis voranging, war kompliziert, zeitaufwändig und kostspielig (die Gebühr für die Arbeitserlaubnis entsprach einem monatlichen Mindestlohn). Die wachsende Arbeitslosigkeit, die in den Jahren 2002-2004 $20 \%$ erreichte, ließ nicht einmal die Diskussion darüber zu, das System der Beschäftigung von Ausländern zu liberalisieren.

Daher war die offizielle Beschäftigung von Ausländern gering. 1990 wurden 3.300 Arbeitsgenehmigungen erteilt, ab 1999 waren es jährlich zwischen 17.000 und 22.000. Interessanterweise wurde die Mehrzahl der Genehmigungen an Experten und Spezialisten aus dem Westen ausgegeben, weil es sich in ihrem Falle für den Arbeitgeber lohnte, die Kosten für ein legales Arbeitsverhältnis zu tragen.

Grundsätzlich stellt sich die Frage nach der Position Polens zur illegalen Arbeit von Migranten aus dem Osten in den Bereichen Landwirtschaft, Bauwesen und in Privathaushalten. Offiziell erklärte die polnische Regierung, gegen jede Form illegaler Beschäftigung sowohl von Polen als auch von Ausländern anzugehen. Dies spiegelte sich in der Ausarbeitung von Rechtsmitteln und der Entwicklung von Institutionen zum Kampf gegen die Grauzone wider. Ab 1997 drohte einem illegal beschäftigten Ausländer die Ausweisung, bis dahin war dies lediglich mit einer Geldstrafe geahndet worden. Einem Ausländer konnte das Visum oder die Einreise nach Polen verweigert werden, wenn der tatsächliche Grund der Einreise nicht dem angegebenen entsprach. Der offiziell erklärte Kampf gegen illegale Beschäftigung wurde jedoch nicht effektiv geführt. Es wurde in keiner Weise versucht, den Zustrom aus der Ukraine zu begrenzen. Im Gegenteil: Die extrem verspätete Einführung der Visumspflicht (erst 2003, unmittelbar vor dem EU-Beitritt) und anschließend die fast automatische Erteilung von Visa zeigten, dass die polnische Regierung an der Aufrechterhaltung eines breiten Zustroms aus dem Osten interessiert war, obwohl sie sich zweifellos darüber im Klaren war, dass ein großer Teil der vermeintlichen Touristen einreiste, um illegal zu arbeiten. Es wurde auch nicht prinzipiell die Einreise verweigert, 


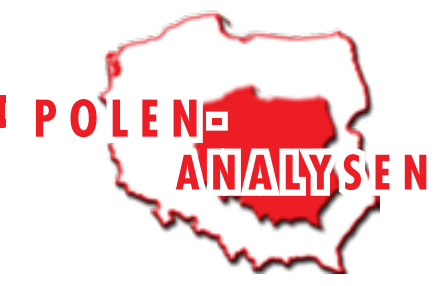

polen-analysen $64 / 10$

wenn das Reiseziel nicht dem angegebenen entsprach. Der Kampf gegen illegale Beschäftigung scheiterte also entweder auf ganzer Linie oder es war nicht beabsichtigt, konsequent gegen die Grauzone vorzugehen, weil dieses offiziell erklärte Ziel gegenüber anderen Zielen in den Hintergrund trat. Wir können davon ausgehen, dass die polnischen Regierungen konsequent eine Politik der stillschweigenden Tolerierung illegaler Beschäftigung von Ausländern betrieben, indem sie die Augen vor diesem wachsenden Phänomen verschlossen.

Änderungen traten erst nach 2005 ein, als gleichzeitig mehrere Faktoren zusammenkamen, die zu einer Liberalisierung der polnischen Migrationspolitik führten. Zum einen wies der Arbeitsmarkt Lücken auf. Das beschleunigte Wachstum der polnischen Wirtschaft nach dem EU-Beitritt, die sinkende Arbeitslosigkeit und die erhöhte Auswanderung führten nach dem Beitritt dazu, dass die Arbeitgeber Druck auf die Regierung ausübten, die Beschäftigung von Arbeitnehmern aus dem Ausland zu erleichtern. Dieser Druck zeigte erstmalig deutliche Wirkung, als 2006 die populistische Partei Samoobrona (Selbstverteidigung) - eine Interessenvertretung reicher Landwirte - an der Regierung beteiligt war und der Posten des Arbeitsministers, verantwortlich u. a. für Fragen der Beschäftigung von Ausländern, einem Vertreter dieser Partei zufiel. Ein weiterer Faktor, der die Regelung der Arbeitsmigration in Polen unabdingbar machte, war der bevorstehende Beitritt Polens zum Schengener Abkommen. Die Kriterien für die Erteilung eines Schengen-Visums sowie sein Preis würden zweifellos den Verkehr an der polnischen Ostgrenze bremsen und sich so negativ auf die Wirtschaftszweige auswirken, die Migranten aus dem Osten beschäftigten.

Daher wurde 2006 die Möglichkeit der Saisonarbeit (bis zu drei Monate im Jahr) in der Landwirtschaft für Bürger aus den östlichen Nachbarstaaten eingeführt. Dies war eine Revolution im polnischen Migrationssystem, weil hier zum ersten Mal ein offizieller Weg der legalen Arbeitsmigration entstand, der nicht vom restriktiven Verfahren der Arbeitsbewilligung beschränkt wurde. Nach weiteren Liberalisierungen in den Jahren 2007 2009 können Bürger aus der Ukraine, Belarus, Russland und Moldawien zurzeit für sechs Monate pro Jahr eine Beschäftigung in einem beliebigen Wirtschaftszweig ausüben, ohne eine Arbeitserlaubnis zu beantragen. Der Arbeitgeber muss lediglich beim örtlichen Arbeitsamt die Absicht melden, ausländische Arbeitskräfte zu beschäftigen. Die Zahl der registrierten Anträge von Arbeitgebern auf Beschäftigung von Ausländern stieg von 249 im Jahr 2006 sprunghaft auf 156.000 im Jahr 2008 an; $90 \%$ davon betrafen Migranten aus der Ukraine.
Parallel zu der neu geschaffenen Option legaler Saisonarbeit wurde das Verfahren zur Bewilligung einer Arbeitserlaubnis liberalisiert (Gebührensenkung, seit 2009 erhebliche Vereinfachung des Verfahrens). Gleichzeitig entfiel für einen Großteil der Ausländer die Auflage der Arbeitserlaubnis, u. a. seit 2004 für alle EU-Bürger und ihre Familienmitglieder. Die polnische Migrationspolitik der letzten Jahre erinnert im Bereich der Arbeitsmigration nur noch geringfügig an die restriktiven Vorschriften der 1990er Jahre, als das Ausstellungsverfahren einer Arbeitserlaubnis scherzhaft das Nichtausstellungsverfahren einer Arbeitserlaubnis genannt wurde.

\section{Ausländer in Polem}

Die Ukrainer stehen mit 16.000 Menschen bei der ausländischen Bevölkerung in Polen insgesamt an der Spitze einer Gruppe, die im Vergleich mit anderen europäischen Staaten verschwindend gering ist. Die letzte Volkszählung von 2002 registrierte 49.000 Ausländer in Polen, die gespeicherten Daten über erteilte Aufenthaltsgenehmigungen lassen auf 84.000 Migranten im Land schließen, was etwa 0,2\% der Gesamtbevölkerung entspricht!

Neben den Ukrainern, die die geographische, kulturelle und sprachliche Nähe sowie ein ausgebautes Einwanderungsnetz nach Polen zieht, sind auch Belarussen und Russen zahlenmäßig stark vertreten. Doch auch dies sind, ähnlich wie die Ukrainer, Gruppen, die in der polnischen Gesellschaft nicht auffallen. Die Saisonarbeiter reisen aus und kommen wieder und diejenigen, die eine längere Aufenthaltserlaubnis haben, assimilieren sich ohne Probleme und verschmelzen unbemerkt mit der polnischen Gesellschaft. Sie lernen die Sprache und Sitten und funktionieren so problemlos im transnationalen Raum zwischen Polen und der Ukraine, ohne die Aufmerksamkeit der polnischen Gesellschaft auf sich zu ziehen.

Eine wichtige Gruppe von Migranten in Polen sind die Vietnamesen. Von den Tausenden vietnamesischer Studenten, die noch in der Volksrepublik Polen ausgebildet worden waren, blieb ein Teil in Polen und verdiente großenteils mit Handel ihr Geld. Sie bildeten den Anfang der vietnamesischen Diaspora in Polen, die vom Innenministerium auf $20.000-50.000$ Personen geschätzt wird, von denen sich aber nur 13.000 legal in Polen aufhalten. Die Vietnamesen genießen aufgrund ihrer eigenen Kultur und des anderen Aussehens die besondere Aufmerksamkeit der Immigrationsforscher in Polen. Sie sind hauptsächlich im Textilhandel tätig, sowohl im Groß- als auch im Kleinhandel; der Durchschnittspole verbindet sie vor allem mit preiswerter, vietnamesischer Schnellgastronomie. Die Nachfrage nach billigen asiatischen Textilien war in den 1990er Jah- 


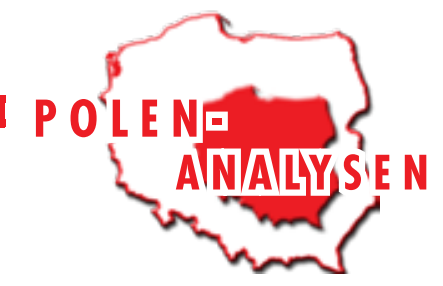

polen-analysen $64 / 10$

ren, in einer aufgrund der wirtschaftlichen Transformation verarmten Gesellschaft, außergewöhnlich groß. Die Handelsumsätze stiegen und mit ihnen der Zustrom weiterer Händler nach Polen. Momentan gründen die Vietnamesen Unternehmen und bilden Handelsstrukturen, die auf einem Netz von Landsleuten basieren - legalen und illegalen vietnamesischen Unternehmern und Arbeitern. Die legal agierenden Geschäftsleute vermieten häufig den neuankommenden Landsleuten Stände unter, an denen diese die mitgeführten Waren verkaufen und so versuchen können, die Schulden zu begleichen, die durch ihre Reise nach Polen entstanden sind. Sie sind vor allem in den großen Städten und der Umgebung zu finden, die größte Gruppe lebt in Warschau. Ein wichtiges Zentrum vietnamesischen Handels war bis zu seiner Schließung 2008 der sogenannte "Jahrmarkt Europa", der größte Basar Polens im größten Stadion von Warschau, ein Mekka aller illegal eingereisten und Handel treibenden Ausländer. Einen großen Teil des Basars nahmen die Vietnamesen ein, die nach Untersuchungen von Aleksandra Grzymała-Kazłowska 1.100 bis 1.200 Stände betrieben, die von 300 vietnamesischen Firmen vermietet wurden. Nach Schließung des Basars (das Stadion wurde abgerissen, zurzeit wird ein neues Stadion für die Fußballeuropameisterschaft 2012 errichtet), wurde Wólka Kosowska, ein kleines Städtchen etwa 25 km von Warschau entfernt, zum Zentrum des vietnamesischen und chinesischen Handels.

Bei den vietnamesischen Migranten ist der illegale Aufenthalt oft mit einer illegalen Einreise verbunden. Diejenigen, die in der ersten Hälfte der 1990er Jahre nach Polen einreisten, kamen zumeist über die grüne Grenze. Spätere Einreisen erfolgten häufig mithilfe falscher oder auf eine andere Person ausgestellter Papiere. Oft verlieren auch Migranten, die legal eingereist sind (mit einem Visum, das z. B. für die Arbeit in einem vietnamesischen Restaurant ausgestellt wurde), ihren legalen Status, wenn sie auf den Basaren Handel treiben.

Die Vietnamesen erscheinen nach außen als geschlossene Gruppe, auch wenn diese durch die Legalität oder Illegalität ihres Aufenthalts und ihren Wohlstand differenziert ist. Aufgrund ihrer kulturellen Distanz lässt sich die Gruppe schwer untersuchen, zumal sie den Kontakt mit Behörden meidet. In dieser Gruppe wurde auch der einzige Fall von unfreiwilliger Arbeit in Polen aktenkundig und vor Gericht gebracht - ein Vietnamese war von seinen Landsleuten zur Arbeit gezwungen worden, um die durch sein Einschleusen entstandenen Schulden abzubezahlen. Schwer zu sagen, wie viele solcher Fälle es tatsächlich gibt.

Die Vietnamesen kommen eher langfristig nach Polen, viele versuchen ihren Aufenthalt zu legalisieren. Gemein- sam mit den Armeniern dominierten sie die beiden Regularisierungskampagnen für Ausländer 2003 und 2007. Einige greifen auch zum Instrument der fiktiven Heirat mit Polen, um eine Aufenthaltserlaubnis zu erhalten. Selbst wenn es sich um eine ziemlich geschlossene Gruppe handelt, haben sich die Vietnamesen in den Großstädten, besonders in Warschau, eingelebt und Akzente im Stadtbild gesetzt; ihre Frühlingsrollen, die »sajgonki«, sind mittlerweile auch bei vielen Polen beliebt.

Zu den Migrantengruppen, die länger in Polen bleiben, gehören auch die Armenier. Sie kamen Anfang der 1990er Jahre noch unter den Bedingungen der visumsfreien Einreise aus den Nachfolgestaaten der UdSSR und ließen sich in Polen nieder - häufig illegal, besonders nachdem 1998 die Visumspflicht eingeführt wurde.

Zu erwähnen sind hier auch Ausländer aus den westlichen Ländern, die besonders Anfang der 1990er Jahre recht zahlreich kamen, als zunehmend internationale Firmen den polnischen Markt entdeckten. Häufig handelte es sich um Mitarbeiter polnischer Herkunft, die von ihren Mutterfirmen in neu eröffnete Niederlassungen geschickt wurden. Die polnische Wirtschaft hatte in der Transformationsphase einen großen Bedarf an Fachleuten, Spezialisten für westliche Technologie und Management sowie an Fremdsprachenlehrern. Westliche Berater, Spezialisten, Manager und Lehrer stellen die größte Gruppe derjenigen, die in den 1990er Jahren eine Arbeitserlaubnis erhielten.

\section{Flüchtlinge und Asylbewerber}

In letzter Zeit hingen in Warschau Plakate, die eine Flüchtlingsfrau mit Kind auf einer Bahnhofsbank mit der Frage "Umsteige- oder Zielbahnhof? « zeigten. Welche Station ist Polen für Flüchtlinge? Die Plakate laden zu einer Ausstellung von Flüchtlingsfotos ein, die sicher auch zur Reflexion über die schwierige Situation dieser Ausländergruppe aufrufen soll. Zurzeit sind Flüchtlinge in Polen - im Vergleich zu anderen Ausländergruppen - deutlich privilegiert. Sie werden nicht nur durch die Genfer Konventionen geschützt, sondern auch durch das in Polen verankerte EU-Asylrecht. Auf die Flüchtlinge und Asylbewerber richten sich das Augenmerk der Migrationsforscher und die spezielle Unterstützung durch europäische Hilfsfonds. Flüchtlinge sind die einzige Gruppe von Ausländern, außer den Heimkehrern, denen eine einjährige Integrationshilfe zusteht. Diese umfasst finanzielle Zuwendungen, Hilfe der regionalen Behörden bei der Wohnungssuche und Polnischkurse.

Bis 1989 war Polen das Herkunftsland von Flüchtlingen, die während des Kalten Krieges - häufig mit Erfolg - in den Ländern Westeuropas Asyl beantragt hatten. 


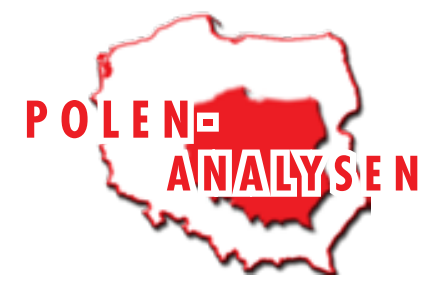

Als 1990 die Schweden eine mehr als hundertköpfige Gruppe von Asylbewerbern, die über Polen ins Land gelangt waren, zurückschickten, wurde Polen praktisch über Nacht von einem Auswandererland zu einem Land, das Flüchtlinge aufnimmt. Der Aufbau der Demokratie brachte es mit sich, dass die westeuropäischen Staaten Polen nicht nur als sicheres Herkunftsland einstuften (und damit polnischen Bürgern nicht mehr den Flüchtlingsstatus einräumten), sondern gleichzeitig als sicheres Drittland, also als Land, in das man Asylbewerber, die durch dieses Land eingereist waren, zurückschicken konnte. Dieser Status wurde durch Polens Beitritt zur Genfer Flüchtlingskonvention und durch den Aufbau institutioneller, verfahrenstechnischer und materieller Grundlagen zur Annahme und Bearbeitung von Asylanträgen in Polen besiegelt.

Der Zustrom von Asylbewerbern nach Polen erreichte allerdings nicht im Entferntesten das Niveau Westeuropas. In den 1990er Jahren wurden in Polen jährlich durchschnittlich ca. 2.000 Asylanträge gestellt, in den Jahren 2000-2008 waren es durchschnittlich gut 6.800 Anträge pro Jahr. Nach 2000 dominierten bei den Asylanträgen die Tschetschenen. Zwischen 2004 und 2008 stellten sie $90 \%$ aller Anträge. Weniger als 3.500 erhielten in den Jahren 1992-2008 einen positiven Bescheid. Es ist allerdings nicht bekannt, wie viele der anerkannten Asylberechtigten in Polen geblieben sind. Folglich gibt es nur wenige Flüchtlinge, allerdings mit unterschiedlicher Herkunft.

Die tschetschenischen Kriegsflüchtlinge erfüllen zumeist die Kriterien der Genfer Konvention (begründete Furcht vor Verfolgung) und ihnen werden andere Formen des Schutzes gewährt: Aufenthaltserlaubnis (seit 2003) und subsidiärer Schutz (seit 2008). Dieser Status erlaubt ihnen, sich legal in Polen aufzuhalten und zu arbeiten, erkennt ihnen aber nicht die Privilegien des Flüchtlingsstatus zu wie den Genfer Pass (und damit die Möglichkeit, aus Polen auszureisen) und die Integrationshilfe. Ihre kulturelle und religiöse Andersartigkeit erschwert ihre Anpassung in Polen. Die Kriegsjahre, verbunden mit Ausbildungslücken und fehlender Arbeitspraxis, wirken sich negativ auf ihre Chancen aus, in Polen Arbeit zu finden. Besonders schwer haben es hier tschetschenische Frauen, die häufig viele Kinder zu versorgen haben und kulturell ausschließlich auf die Hausarbeit vorbereitet sind. Vom Krieg traumatisiert und von zuhause nicht mit dem Ethos der Bildung als eigenständigem Wert ausgestattet, fällt den tschetschenischen Kindern das Lernen in polnischen Schulen schwer. All dies führt dazu, dass viele Tschetschenen von ihrem Aufenthalt in Polen enttäuscht sind. Die Tschetschenen verfü- gen über ein ausgebautes Migrationsnetz in den westlichen Staaten und wissen von der deutlich umfangreicheren sozialen Versorgung in anderen Ländern. Daher versuchen sie, zu ihren dort lebenden Verwandten und Bekannten zu gelangen. Gleichzeitig schicken die Staaten Tschetschenen, selbst wenn es ihnen gelingt, über die Grenze zu gelangen, gemäß der Dublin II-Verordnung nach Polen zurück.

\section{Die Polen und ihr Bild vom Fremden}

Haben die Migranten Polens Erscheinungsbild nach 1989 verändert? Eindeutig ja. In den Großstädten durch die Präsenz vietnamesischer und chinesischer Händler, durch türkische Restaurants, ausländische Studenten und Geschäftsleute. In den polnischen Haushalten über das Fernsehen, das eine neue Erfolgsformel fand, indem Ausländer oder Polen anderer ethnischer Herkunft in den Unterhaltungsprogrammen und Serien auftreten wie z. B. in der Show mit Vertretern der EUStaaten "Europa da się lubić» (Liebenswertes Europa) oder in den Serien mit farbigen Schauspielern (»Rodzina zastępca» - Ersatzfamilie oder »Barwy szczęścia» - Farben des Glücks). Die größte Gruppe der legalen und der illegalen Ausländer in Polen, die Ukrainer, stehen allerdings nach wie vor im Schatten.

Ausländerfragen finden selten Einzug in die Zeitungen und Tagesmedien. Manchmal rütteln Journalisten mit einem Bericht über ihrer Meinung nach ungerecht behandelte Asylbewerber auf oder über Ausländer mit ungeklärter Rechtsposition, die von einem Schicksalsschlag getroffen wurden. Zuletzt bewegte die Öffentlichkeit der Fall einer todkranken Ukrainerin, die eine polnische Familie suchte, die ihre vier Kinder aufnehmen könnte, damit diese nicht nach ihrem Tod in ein ukrainisches Kinderheim kämen.

Wie Meinungsumfragen ergeben, waren Polen generell positiv gegenüber Ausländern eingestellt. (Lediglich im Umbruch der 1990er Jahre und nach dem Jahr 2000 nahm das Misstrauen zu.) Ebenso stößt die illegale Beschäftigung vor allem von Ukrainern auf wenig Ablehnung. Die Polen, die sich noch an jene Zeiten erinnern, als sie selbst illegal auf ihren Reisen nach Westen dazuverdienten, blicken mit Verständnis auf die Ukrainer, die in Polen arbeiten. Ihre Schwarzarbeit werten sie als Selbsthilfe in einer schwierigen Lage und nicht als Rechtsbruch oder unlautere Konkurrenz.

\section{Kein Einwanderungsland}

Ist Polen nach 1989 zu einem Einwanderungsland nach dem Vorbild der Staaten West- und Südeuropas geworden? Eindeutig nein. Die nach wie vor hohe Emigration 


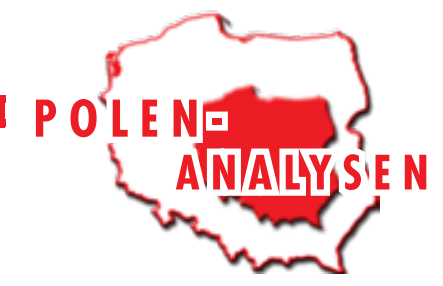

und die - im Vergleich zu anderen europäischen Staaten - verschwindend geringe Einwanderung stützen die Behauptung, dass Polen trotz des Ausländerzustroms der letzten 20 Jahre kein Einwanderungsland geworden ist. Die Einwanderung in Polen ist im Gegensatz zu den Staaten Westeuropas nach wie vor kein Thema in der öffentlichen Debatte. Das Phänomen Einwanderung war nach 1989 ein neues Betätigungsfeld für verschiedene politische Akteure. Zunächst traten jene Instanzen auf den Plan, die Fälle regeln mussten, für die es kein Regelwerk gab. Neben der Regierung betätigten sich hier auch andere Gruppen wie z. B. NGOs und internationale Organisationen. Wichtig ist jedoch, dass die Frage der Migration nie politisiert wurde. Keine politische Partei nimmt in ihrem Programm Stellung zur Migration. Eine öffentliche Debatte zum Thema Einwanderung gibt es im Prinzip nicht, die Migrationspolitik wurde von einem recht begrenzten Kreis von Beamten und wenigen regierungsfernen Organisationen entwickelt. Ein Faktor, der über die Gestaltung der polnischen Migrationspolitik entschied, war die Vorbereitung auf die Europäische Union und später der Beitritt.

Europa wurde nach 1989 zum Bezugspunkt in der gesamten politischen und wirtschaftlichen Entwicklung, was natürlich auch die Migration einschloss. Die polnischen Entscheidungsträger, die vor der Notwendigkeit standen, die Kriterien für Ein- und Auswanderung festzulegen, schauten nach Westen und nutzten dabei die Erfahrungen und ausgearbeiteten Lösungen der westlichen Staaten. Agnieszka Weinar stellt in ihrer Arbeit über die Europäisierung der polnischen Migrationspolitik überzeugend dar, dass durch diesen Lernprozess und die Anwendung westlicher Politik auf die polnische Migrationspolitik von Beginn an die in Europa aktuellen Diskurse über Migration transplantiert wurden sowohl unter sicherheitspolitischen als auch humanitären Gesichtspunkten. Die Migration wurde als Quelle unterschiedlicher Bedrohungen angesehen und als Bedrohung an sich. Die Erfahrungen Westeuropas lehrten, dass eine große Einwanderung Probleme aufwirft, woraus man fol- gerte, dass man sie besser auf niedrigem Niveau hält. Die Philosophie der Null-Einwanderung drang schnell nach Polen durch, begünstigt von wirtschaftlichen Faktoren, besonders von der hohen Arbeitslosigkeit in Polen in der Zeit des Umbruchs. Die Beschränkung der Einwanderung durch die Sicherung der Ostgrenze, die in Zukunft die EU-Ostgrenze und später die Ostgrenze des Schengen-Raums werden sollte, geschah auch auf Druck der westlichen Nachbarn und später der EU.

Gleichzeitig drang das humanitäre Ausmaß der Entwicklung einer europäischen Politik durch, aktuell insbesondere bei den Asylgesetzen. Die polnische Migrationsgesetzgebung wurde von Beginn an genauestens von den NGOs überwacht, die zum Schutz von Ausländerrechten, vor allem von Flüchtlingen arbeiteten. Wie Vertreter der staatlichen Verwaltung und besagter Organisationen glaubhaft versichern, war die Zusammenarbeit im Bereich des Monitorings und der Rechtsanpassung im Hinblick auf die Menschenrechte von Beginn an sehr erfolgreich.

Die Vorbereitung auf die EU-Mitgliedschaft und besonders die Verpflichtung, den gesamten Acquis communautaire im Bereich Recht und Inneres ohne Verhandlungsmöglichkeit zu übernehmen, besiegelten im Prinzip nur den bestehenden Prozess des Lernens von Europa. In diesem Kontext muss jedoch betont werden, dass Polen trotz des sehr geringen Zustroms eine hochentwickelte und detailliert geregelte Ausländerpolitik nach europäischem Vorbild ausgearbeitet hat. Polens Ausgangslage war der Situation, in der die Migrationspolitik der EU-Staaten und der EU selbst entstand, diametral entgegengesetzt. Die Rechtslösungen wurden in der Union ausgearbeitet und gelangten anschließend als EU-Normen im Eiltempo nach Polen und in andere Staaten Ostmitteleuropas, ohne das Spezifische dieser Region zu berücksichtigen. Dies wurde besonders deutlich, als die Visumspflicht mit den Nachbarn im Osten eingeführt werden musste, die nicht im Interesse der betroffenen Staaten lag.

Übersetzung aus dem Polnischen: Friederike Frost

\section{Über die Autorin}

Anna Kicinger ist seit 2004 wissenschaftliche Mitarbeiterin am Mitteleuropäischen Forum für Migrations- und Bevölkerungsforschung in Warschau [Środkowoeuropejskie Forum Badań Migracyjnych i Ludnościowych], Forschungsschwerpunkt Migrationspolitik. Zu diesem Thema verfasste sie zahlreiche Publikationen, zuletzt erschien von ihr: Beyond the focus on Europeanisation: Polish Migration Policy 1989-2004, in: Journal of Ethnic and Migration Studies 2009, vol. 35(1).

Dieser Beitrag ist ein Vorabdruck aus dem »Jahrbuch Polen 2010 Migration« des Deutschen Polen-Instituts, das im Frühjahr 2010 im Harrassowitz Verlag, Wiesbaden, erscheinen wird (siehe Lesehinweis auf S. 21). 


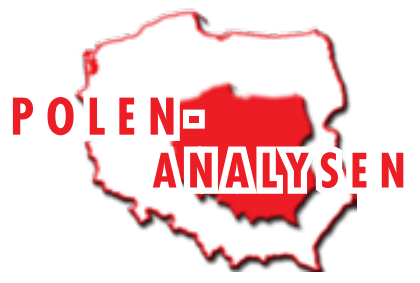

Tabellen und Grafiken

\section{Statistiken zu Visa, Niederlassungserlaubnis und Flüchtlingen in Polen}

\section{Anzahl der ausgegebenen Visa 2006*}

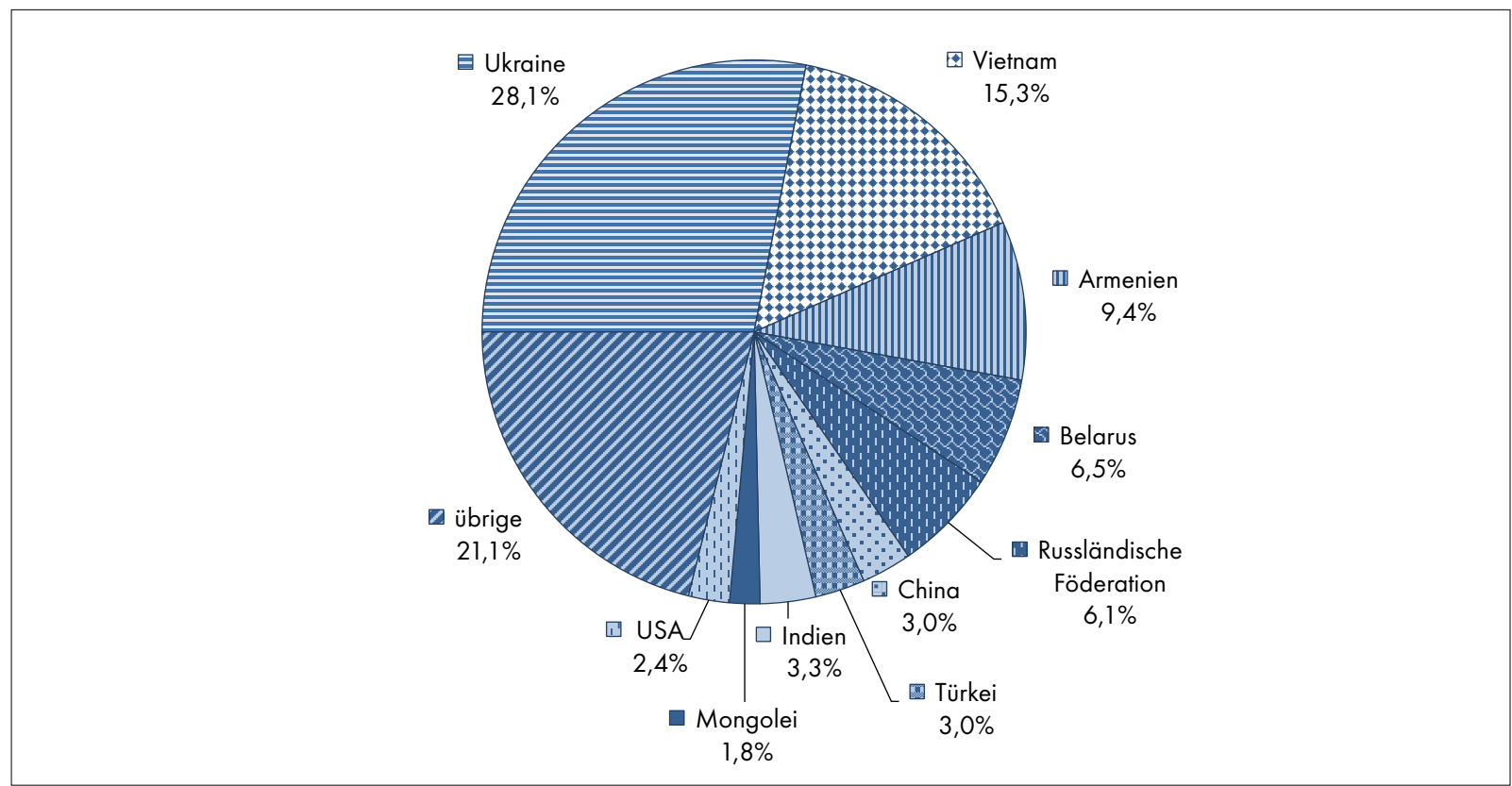

\begin{tabular}{|c|c|c|c|c|}
\hline & $\begin{array}{c}\text { Visum mit } \\
\text { Arbeitserlaubnis }\end{array}$ & $\begin{array}{c}\text { Visum mit } \\
\text { Aufenthaltserlaubnis }\end{array}$ & Summe & $\%$ \\
\hline alle Staatsangehörigkeiten & 11 & 10.939 & 10.950 & 100 \\
\hline \multicolumn{5}{|c|}{ darunter am stärksten vertreten: } \\
\hline Ukraine & 2 & 3.072 & 3.074 & 28,1 \\
\hline Vietnam & 1 & 1.679 & 1.680 & 15,3 \\
\hline Armenien & - & 1.032 & 1.032 & 9,4 \\
\hline Belarus & - & 707 & 707 & 6,5 \\
\hline Russländische Föderation & 2 & 667 & 669 & 6,1 \\
\hline China & 1 & 326 & 327 & 3,0 \\
\hline Türkei & - & 325 & 325 & 3,0 \\
\hline Indien & - & 360 & 360 & 3,3 \\
\hline Mongolei & - & 197 & 197 & 1,8 \\
\hline USA & 1 & 266 & 267 & 2,4 \\
\hline $\begin{array}{l}\text { ausgewählte Nationen } \\
\text { insgesamt }\end{array}$ & 7 & 8.631 & 8.638 & 78,9 \\
\hline
\end{tabular}

${ }^{*}$ Es handelt sich bei den Angaben um die Nationen, die zahlenmäßig am stärksten vertreten sind.

Die Angaben beziehen sich nur aufVisa, die von den Woiwoden in Polen oder den entsprechenden Einrichtungen des polnischen Grenzschutzes ausgegeben wurden. Es werden nicht die Visa berücksichtigt, die von den polnischen diplomatischen und konsularischen Vertretungen im Ausland ausgestellt wurden.

Die Angaben beziehen sich nur auf die ausgegebenen Visa und nicht auf die Anzahl der gestellten Visumsanträge.

Quelle: Urząd do Spraw Cudzoziemców [Amt für Ausländerangelegenheiten]: Dane liczbowe dotyczące postępowań prowadzonych wobec cudzoziemców w latach 2006-2008 [Daten zu Verfahren gegenüber Ausländern in den Jahren 2006-2008], www.udsc.gov.pl (abgerufen am 29.01.2010). 


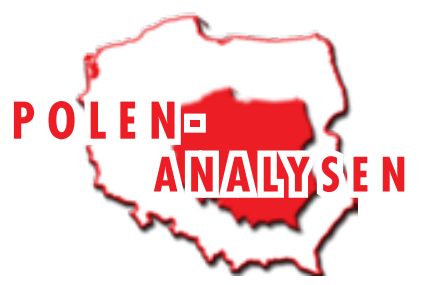

\section{Anzahl der ausgegebenen Visa 2007*}

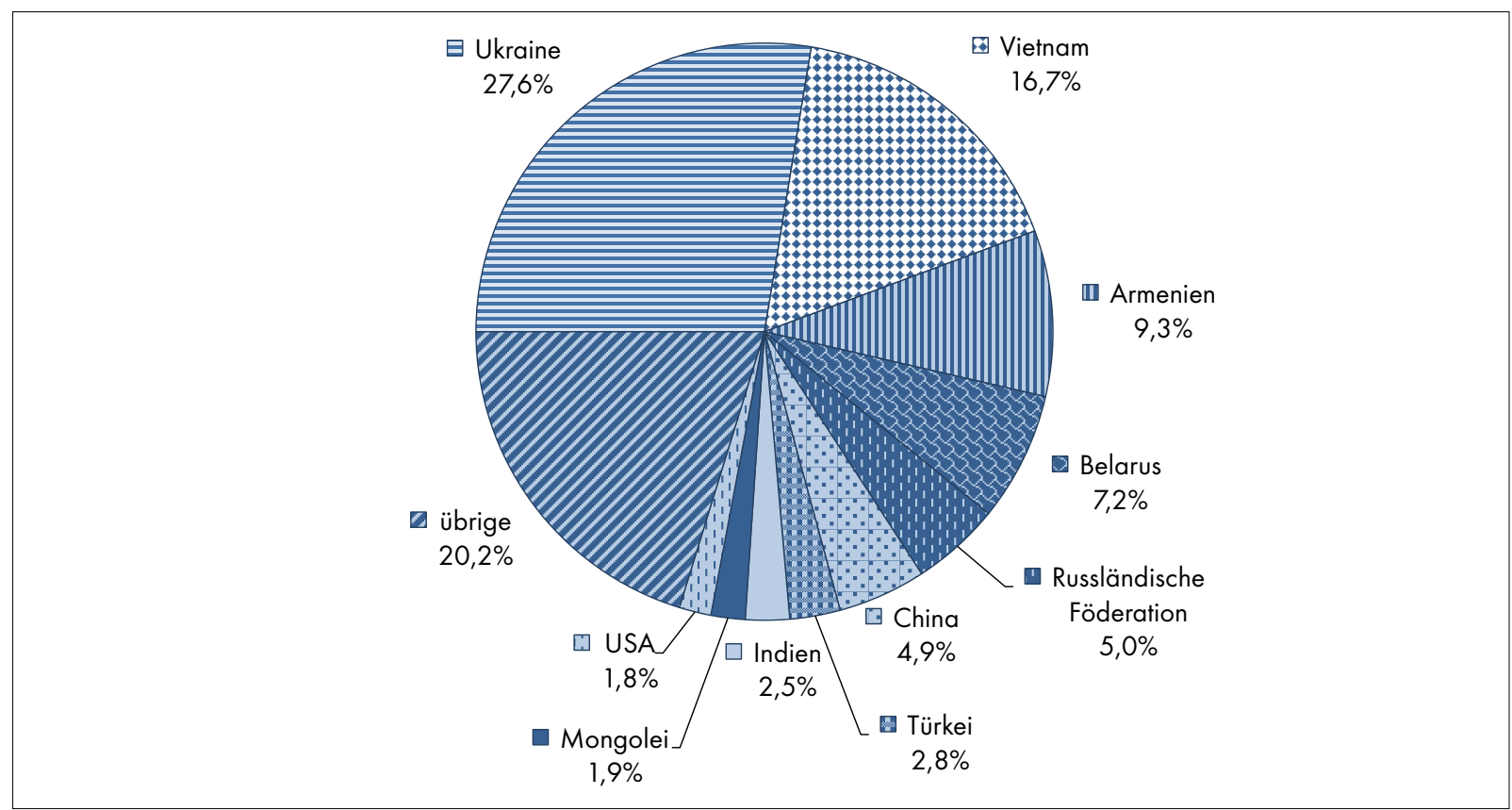

\begin{tabular}{|c|c|c|c|c|}
\hline & $\begin{array}{c}\text { Visum mit } \\
\text { Arbeitserlaubnis }\end{array}$ & $\begin{array}{c}\text { Visum mit } \\
\text { Aufenthaltserlaubnis }\end{array}$ & Summe & $\%$ \\
\hline alle Staatsangehörigkeiten & 32 & 15.830 & 15.862 & 100 \\
\hline \multicolumn{5}{|c|}{ darunter am stärksten vertreten: } \\
\hline Ukraine & 14 & 4.364 & 4.378 & 27,6 \\
\hline Vietnam & - & 2.653 & 2.653 & 16,7 \\
\hline Armenien & - & 1.473 & 1.473 & 9,3 \\
\hline Belarus & - & 1.148 & 1.148 & 7,2 \\
\hline Russländische Föderation & 1 & 789 & 790 & 5,0 \\
\hline China & 11 & 773 & 784 & 4,9 \\
\hline Türkei & - & 447 & 447 & 2,8 \\
\hline Indien & - & 393 & 393 & 2,5 \\
\hline Mongolei & - & 303 & 303 & 1,9 \\
\hline USA & - & 284 & 284 & 1,8 \\
\hline $\begin{array}{l}\text { ausgewählte Nationen } \\
\text { insgesamt }\end{array}$ & 26 & 12.627 & 12.653 & 79,8 \\
\hline
\end{tabular}

${ }^{*}$ Es handelt sich bei den Angaben um die Nationen, die zahlenmäßig am stärksten vertreten sind.

Die Angaben beziehen sich nur auf Visa, die von den Woiwoden in Polen oder den entsprechenden Einrichtungen des polnischen Grenzschutzes ausgegeben wurden. Es werden nicht die Visa berücksichtigt, die von den polnischen diplomatischen und konsularischen Vertretungen im Ausland ausgestellt wurden.

Die Angaben beziehen sich nur auf die ausgegebenen Visa und nicht auf die Anzahl der gestellten Visumsanträge.

Quelle: Urząd do Spraw Cudzoziemców [Amt für Ausländerangelegenheiten]: Dane liczbowe dotyczące postępowań prowadzonych wobec cudzoziemców w latach 2006-2008 [Daten zu Verfahren gegenüber Ausländern in den Jahren 2006-2008], www.udsc.gov.pl (abgerufen am 29.01.2010). 


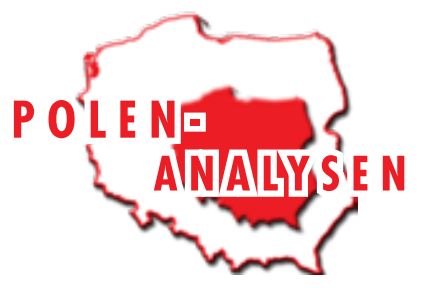

\section{Anzahl der ausgegebenen Visa 2008*}

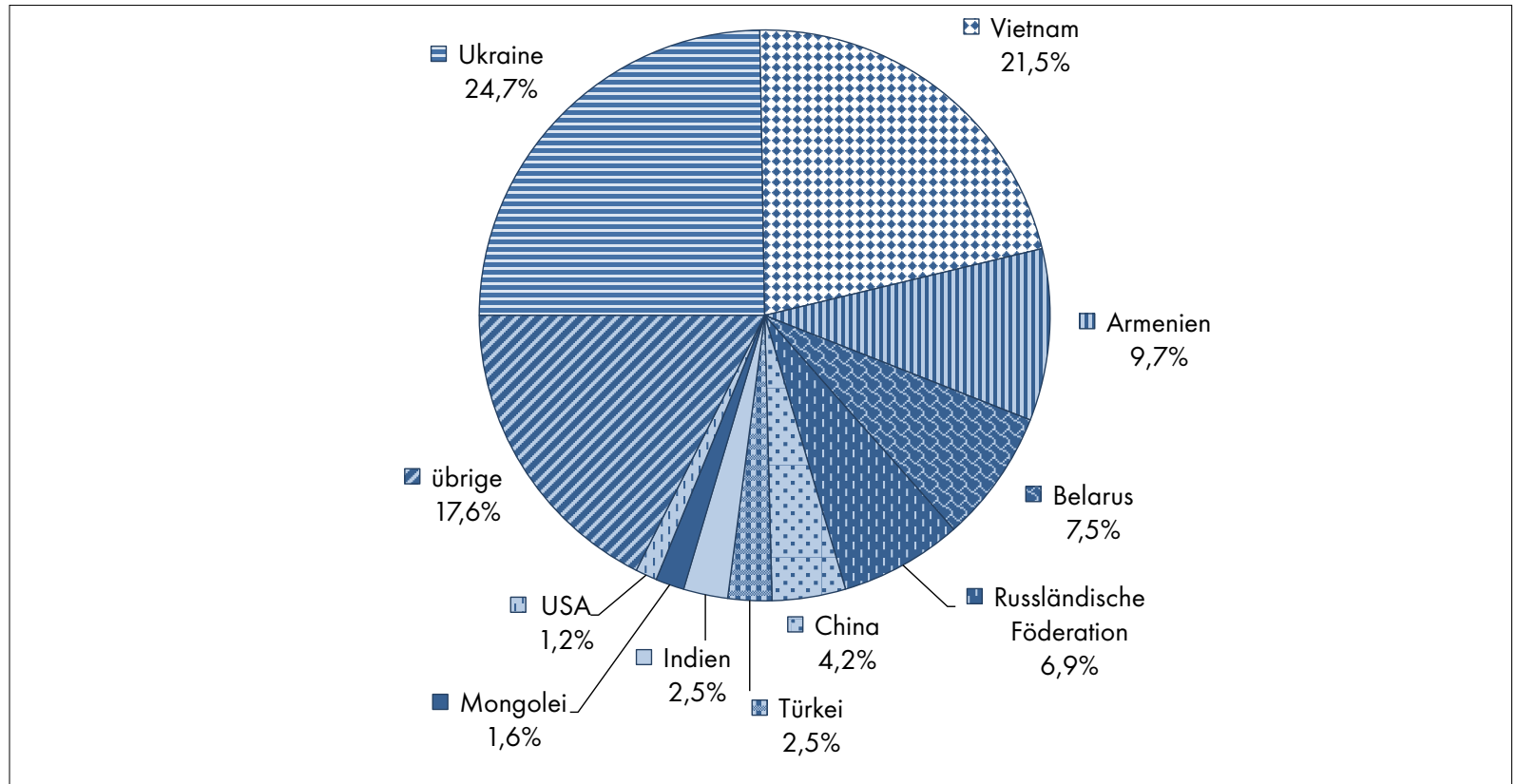

\begin{tabular}{|c|c|c|c|c|}
\hline & Visum für Polen & $\begin{array}{l}\text { Visum für den } \\
\text { Schengenraum }\end{array}$ & Summe & $\%$ \\
\hline alle Staatsangehörigkeiten & 21.863 & 2.132 & 23.995 & 100 \\
\hline \multicolumn{5}{|c|}{ darunter am stärksten vertreten: } \\
\hline Ukraine & 5.440 & 494 & 5.934 & 24,7 \\
\hline Vietnam & 5.158 & 3 & 5.161 & 21,5 \\
\hline Armenien & 2.310 & 25 & 2.335 & 9,7 \\
\hline Belarus & 1.540 & 262 & 1.802 & 7,5 \\
\hline Russländische Föderation & 963 & 704 & 1.667 & 6,9 \\
\hline China & 940 & 59 & 999 & 4,2 \\
\hline Türkei & 574 & 23 & 597 & 2,5 \\
\hline Indien & 514 & 87 & 601 & 2,5 \\
\hline Mongolei & 384 & 5 & 389 & 1,6 \\
\hline USA & 294 & - & 294 & 1,2 \\
\hline $\begin{array}{l}\text { ausgewählte Nationen } \\
\text { insgesamt }\end{array}$ & 18.117 & 1.662 & 19.779 & 82,4 \\
\hline
\end{tabular}

${ }^{*}$ Es handelt sich bei den Angaben um die Nationen, die zahlenmäßig am stärksten vertreten sind.

Die Angaben beziehen sich nur auf Visa, die von den Woiwoden in Polen oder den entsprechenden Einrichtungen des polnischen Grenzschutzes ausgegeben wurden. Es werden nicht die Visa berücksichtigt, die von den polnischen diplomatischen und konsularischen Vertretungen im Ausland ausgestellt wurden.

Die Angaben beziehen sich nur auf die ausgegebenen Visa und nicht auf die Anzahl der gestellten Visumsanträge.

Quelle: Urząd do Spraw Cudzoziemców [Amt für Ausländerangelegenheiten]: Dane liczbowe dotyczące postępowań prowadzonych wobec cudzoziemców w latach 2006-2008 [Daten zu Verfahren gegenüber Ausländern in den Jahren 2006-2008], www.udsc.gov.pl (abgerufen am 29.01.2010). 


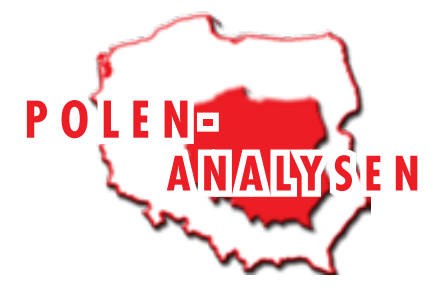

\section{Ausgegebene Visa 2006-2008*}

\begin{tabular}{|l|c|c|}
\hline & Summe aller Visa 2006-2008 & \% \\
alle Staatsangehörigkeiten & 50.807 & $\mathbf{1 0 0}$ \\
\hline darunter am stärksten vertreten: & & 26,3 \\
Ukraine & 13.386 & 18,7 \\
\hline Vietnam & 9.494 & 9,5 \\
Armenien & 4.840 & 7,2 \\
Belarus & 3.657 & 6,2 \\
Russländische Föderation & 3.126 & 4,2 \\
China & 2.110 & 2,7 \\
Türkei & 1.369 & 2,7 \\
Indien & 1.354 & 1,7 \\
Mongolei & 889 & 1,7 \\
\hline USA & 845 & 80,8 \\
\hline ausgewählte Nationen insgesamt & 41.070 & \\
\hline
\end{tabular}

\section{Ausgegebene Visa 2009*}

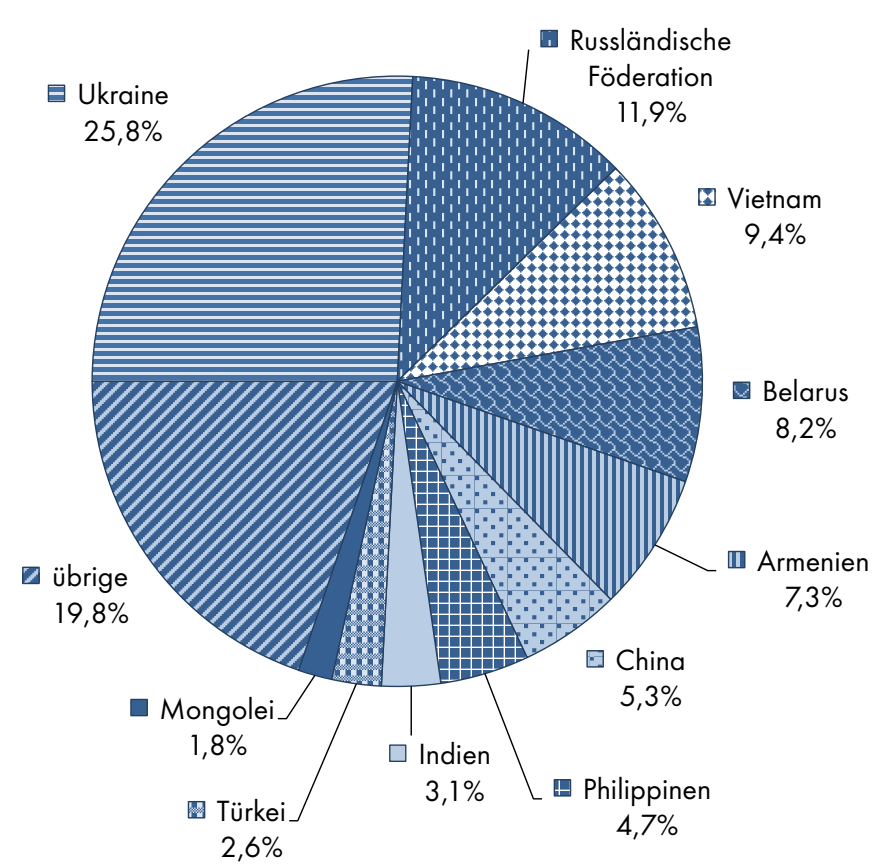

${ }^{*}$ Es handelt sich bei den Angaben um die Nationen, die zahlenmäßig am stärksten vertreten sind. Die Angaben beziehen sich nur aufVisa, die von den Woiwoden in Polen oder den entsprechenden Einrichtungen des polnischen Grenzschutzes ausgegeben wurden. Es werden nicht die Visa berücksichtigt, die von den polnischen diplomatischen und konsularischen Vertretungen im Ausland ausgestellt wurden.

Die Angaben beziehen sich nur auf die ausgegebenen Visa und nicht auf die Anzahl der gestellten Visumsanträge.

Quelle: Urząd do Spraw Cudzoziemców [Amt für Ausländerangelegenheiten]: Dane liczbowe dotyczące postępowań prowadzonych wobec cudzoziemców w 2009 r. [Daten zu Verfahren gegenüber Ausländern im Jahr 2009], www.udsc.gov.pl (abgerufen am 29.01.2010). 


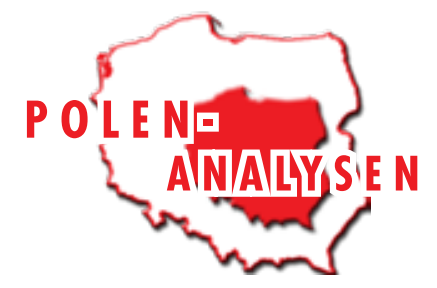

\section{Ausgegebene Visa 2009*}

\begin{tabular}{|c|c|c|c|}
\hline & Visum für Polen & $\begin{array}{l}\text { Visum für den } \\
\text { Schengenraum }\end{array}$ & insgesamt \\
\hline alle Staatsangehörigkeiten & 21.039 & 2.889 & 23.912 \\
\hline \multicolumn{4}{|c|}{ darunter am stärksten vertreten: } \\
\hline Ukraine & 5.645 & 527 & 6.172 \\
\hline Russländische Föderation & 1.814 & 1.031 & 2.845 \\
\hline Vietnam & 2.246 & 8 & 2.254 \\
\hline Belarus & 1.736 & 224 & 1.960 \\
\hline Armenien & 1.728 & 26 & 1.754 \\
\hline China & 1.220 & 57 & 1.277 \\
\hline Philippinen & 587 & 539 & 1.126 \\
\hline Indien & 659 & 85 & 744 \\
\hline Türkei & 572 & 56 & 628 \\
\hline Mongolei & 412 & 15 & 427 \\
\hline $\begin{array}{l}\text { ausgewählte Nationen } \\
\text { insgesamt }\end{array}$ & 16.619 & 2.568 & 19.187 \\
\hline
\end{tabular}

Anm.: Im Vergleich zu 2006-2008: erteilte Visa an US-Amerikaner im Jahr 2009 für Polen 194, für den Schengenraum 0.

${ }^{*}$ Es handelt sich bei den Angaben um die Nationen, die zablenmäßig am stärksten vertreten sind.

Die Angaben beziehen sich nur aufVisa, die von den Woiwoden in Polen oder den entsprechenden Einrichtungen des polnischen Grenzschutzes ausgegeben wurden. Es werden nicht die Visa berücksichtigt, die von den polnischen diplomatischen und konsularischen Vertretungen im Ausland ausgestellt wurden.

Die Angaben beziehen sich nur auf die ausgegebenen Visa und nicht auf die Anzahl der gestellten Visumsanträge.

Quelle: Urząd do Spraw Cudzoziemców [Amt für Ausländerangelegenheiten]: Dane liczbowe dotyczące postępowań prowadzonych wobec cudzoziemców w 2009 r. [Daten zu Verfahren gegenüber Ausländern im Jahr 2009], www.udsc.gov.pl (abgerufen am 29.01.2010).

\section{Erteilte Niederlassungserlaubnis 2006-2008}

\begin{tabular}{|l|c|c|}
\hline \multicolumn{1}{|c|}{} & Anzahl der Personen 2006-2008 & \% \\
\hline Ausländer insgesamt & 10.004 & 100 \\
\hline darunter am stärksten vertreten: & & 47,3 \\
Ukraine & 4.732 & 18,1 \\
\hline Belarus & 1.809 & 7,6 \\
Russländische Föderation & 765 & 4,2 \\
Vietnam & 425 & 3,2 \\
Armenien & 317 & 80,4 \\
\hline ausgewählte Nationen insgesamt & 8.048 & \\
\hline
\end{tabular}

Quelle: Urzad do Spraw Cudzoziemców [Amt für Ausländerangelegenheiten]: Dane liczbowe dotyczące postępowań prowadzonych wobec cudzoziemców w latach 2006-2008, [Daten zu Verfahren gegenüber Ausländern in den Jahren 2006-2008], www.udsc.gov.pl (abgerufen am 29.01.2010). 


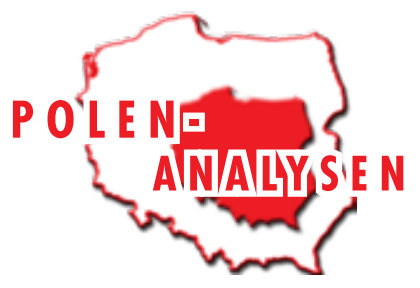

Erteilte Niederlassungserlaubnis 2008

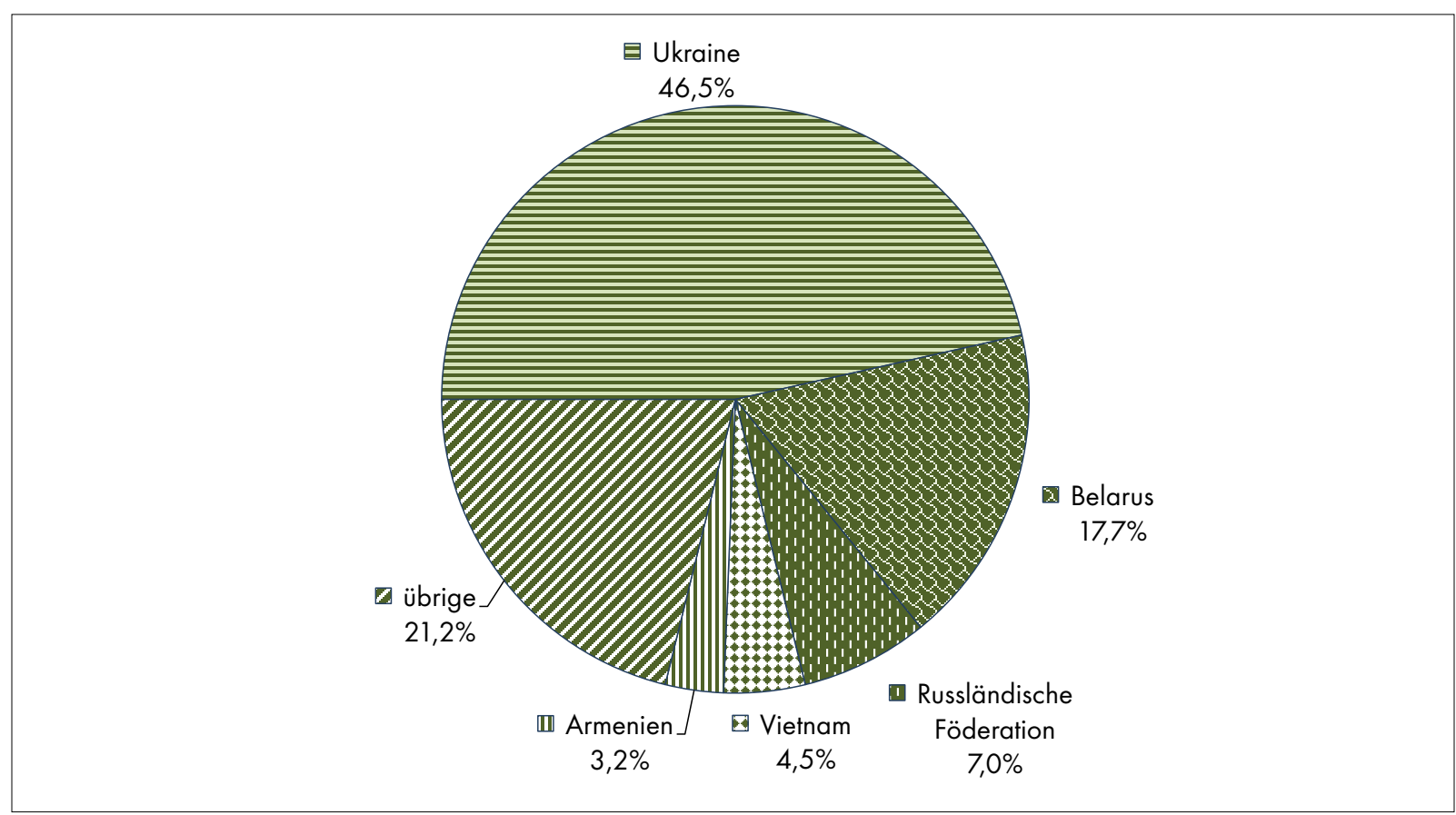

\begin{tabular}{|l|c|c|}
\hline \multicolumn{2}{|c|}{ Anzahl der Personen 2008 } & $\%$ \\
\hline Ausländer insgesamt & 3.625 & 100 \\
\hline darunter am stärksten vertreten: & \multicolumn{2}{|c|}{} \\
Ukraine & 1.685 & 46,5 \\
\hline Belarus & 640 & 17,7 \\
\hline Russländische Föderation & 255 & 7,0 \\
Vietnam & 162 & 4,5 \\
Armenien & 116 & 3,2 \\
\hline ausgewählte Nationen insgesamt & 2.858 & 78,8 \\
\hline
\end{tabular}

Quelle: Urząd do Spraw Cudzoziemców [Amt für Ausländerangelegenheiten]: Dane liczbowe dotyczące postępowań prowadzonych wobec cudzoziemców w latach 2006-2008, [Daten zu Verfahren gegenüber Ausländern in den Jahren 2006-2008], www.udsc.gov.pl (abgerufen am 29.01.2010). 


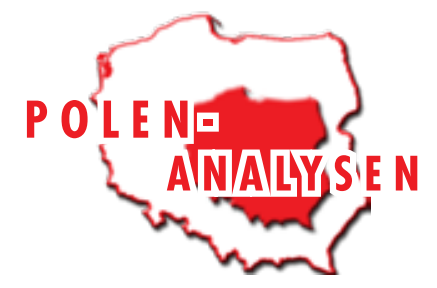

Nicht erteilte Niederlassungserlaubnis 2006-2008

\begin{tabular}{|c|c|c|}
\hline & Anzahl der Personen 2006-2008 & $\%$ \\
\hline Ausländer insgesamt & 804 & 100 \\
\hline \multicolumn{3}{|l|}{ darunter am stärksten vertreten: } \\
\hline Ukraine & 337 & 41,9 \\
\hline Belarus & 131 & 16,3 \\
\hline Russländische Föderation & 70 & 8,7 \\
\hline Armenien & 47 & 5,8 \\
\hline Vietnam & 41 & 5,1 \\
\hline ausgewählte Nationen insgesamt & 626 & 77,9 \\
\hline
\end{tabular}

Quelle: Urząd do Spraw Cudzoziemców [Amt für Ausländerangelegenheiten]: Dane liczbowe dotyczące postępowań prowadzonych wobec cudzoziemców w latach 2006-2008, [Daten zu Verfahren gegenüber Ausländern in den Jahren 2006-2008], www.udsc.gov.pl (abgerufen am 29.01.2010).

Nicht erteilte Niederlassungserlaubnis 2008

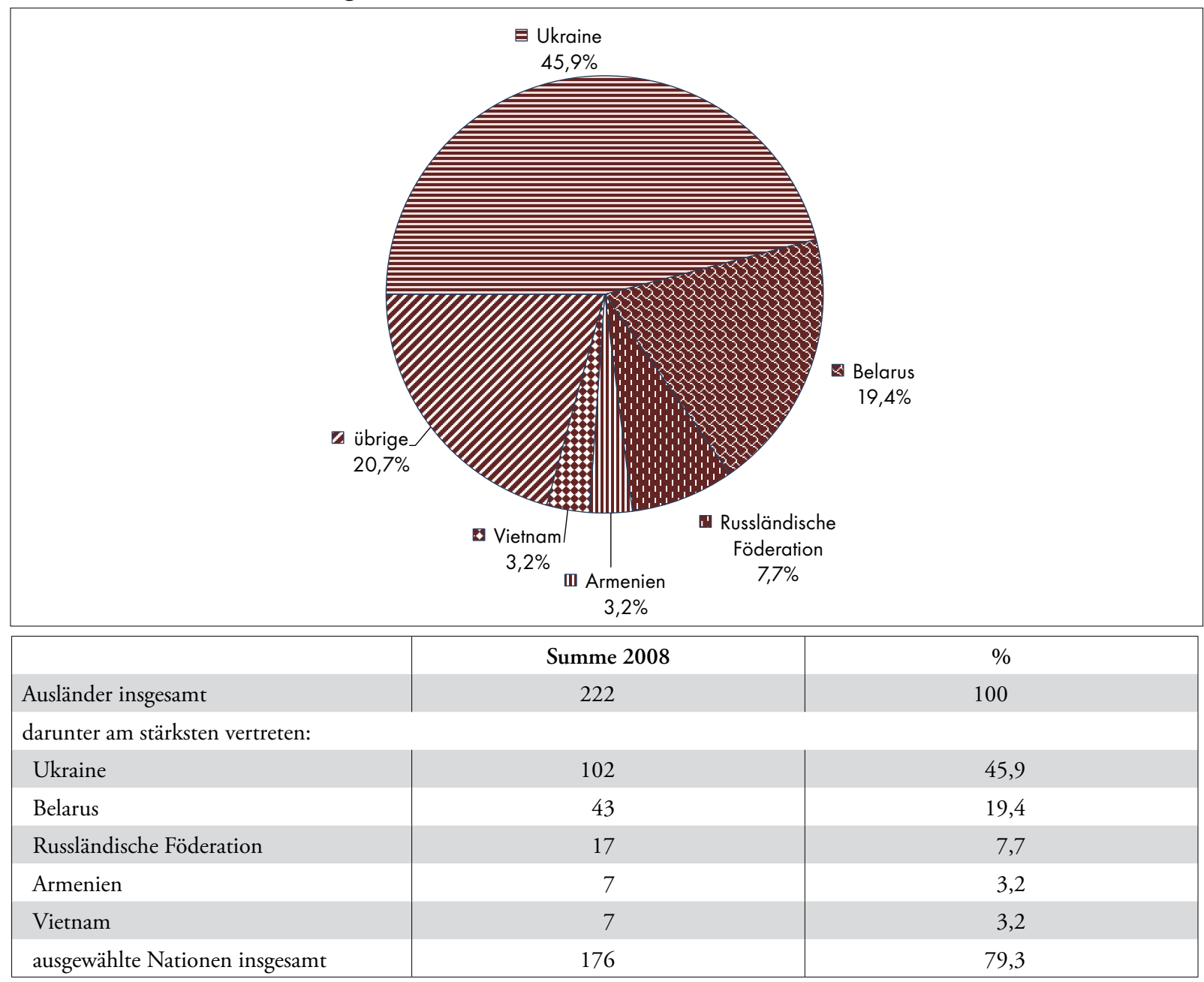

Quelle: Urząd do Spraw Cudzoziemców [Amt für Ausländerangelegenheiten]: Dane liczbowe dotyczące postępowań prowadzonych wobec cudzoziemców w latach 2006-2008, [Daten zu Verfahren gegenüber Ausländern in den Jahren 2006-2008], www.udsc.gov.pl (abgerufen am 29.01.2010). 


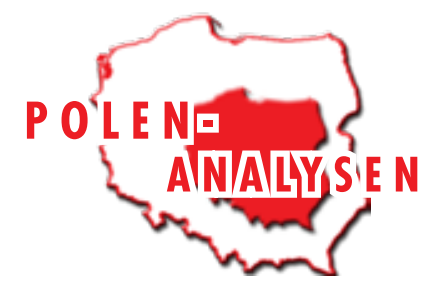

Niederlassungserlaubnis, eingestellte Verfahren 2006-2008

\begin{tabular}{|c|c|c|}
\hline & Anzahl der Personen 2006-2008 & $\%$ \\
\hline Ausländer insgesamt & 815 & 100 \\
\hline \multicolumn{3}{|l|}{ darunter am stärksten vertreten: } \\
\hline Ukraine & 317 & 38,9 \\
\hline Belarus & 95 & 11,7 \\
\hline Russländische Föderation & 59 & 7,2 \\
\hline Armenien & 48 & 5,9 \\
\hline Vietnam & 45 & 5,5 \\
\hline ausgewählte Nationen insgesamt & 564 & 69,2 \\
\hline
\end{tabular}

Quelle: Urząd do Spraw Cudzoziemców [Amt für Ausländerangelegenheiten]: Dane liczbowe dotyczace postępowań prowadzonych wobec cudzoziemców w latach 2006-2008, [Daten zu Verfahren gegenüber Ausländern in den Jahren 2006-2008], www.udsc.gov.pl (abgerufen am 29.01.2010).

Niederlassungserlaubnis, eingestellte Verfahren 2008

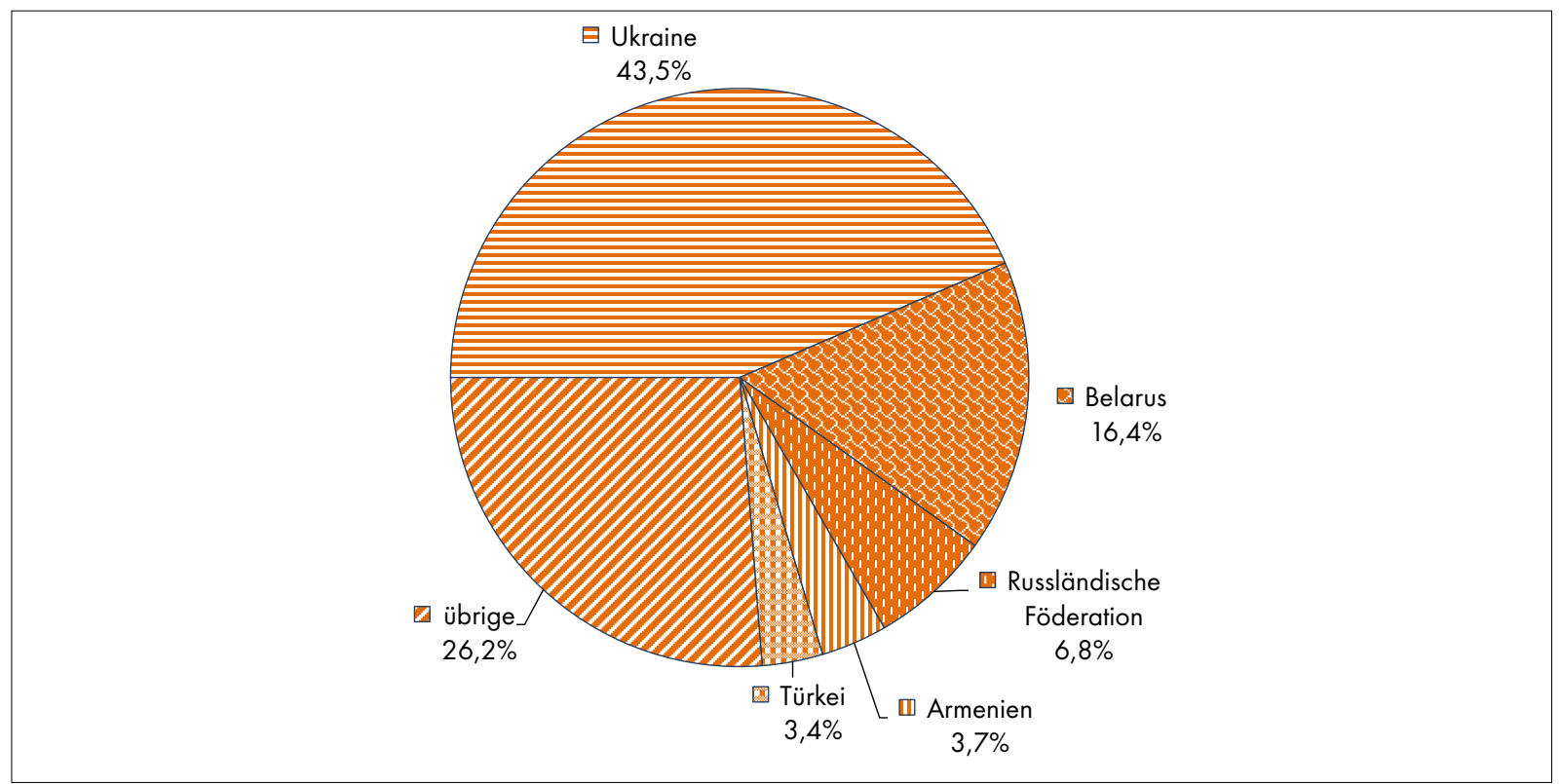

\begin{tabular}{|c|c|c|}
\hline & Summe 2008 & $\%$ \\
\hline Ausländer insgesamt & 324 & 100 \\
\hline \multicolumn{3}{|l|}{ darunter am stärksten vertreten: } \\
\hline Ukraine & 141 & 43,5 \\
\hline Belarus & 53 & 16,4 \\
\hline Russländische Föderation & 22 & 6,8 \\
\hline Armenien & 12 & 3,7 \\
\hline Türkei & 11 & 3,4 \\
\hline ausgewählte Nationen insgesamt & 239 & 73,8 \\
\hline
\end{tabular}

Quelle: Urząd do Spraw Cudzoziemców [Amt für Ausländerangelegenheiten]: Dane liczbowe dotyczące postępowań prowadzonych wobec cudzoziemców w latach 2006-2008, [Daten zu Verfahren gegenüber Ausländern in den Jahren 2006-2008], www.udsc.gov.pl (abgerufen am 29.01.2010). 


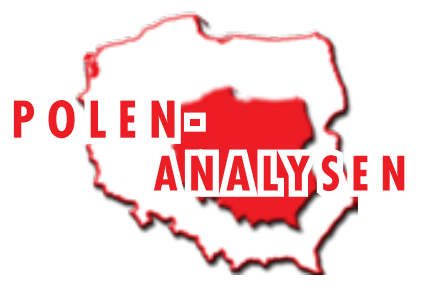

Gestellte Anträge auf Anerkennung des Flüchtlingsstatus 2009*

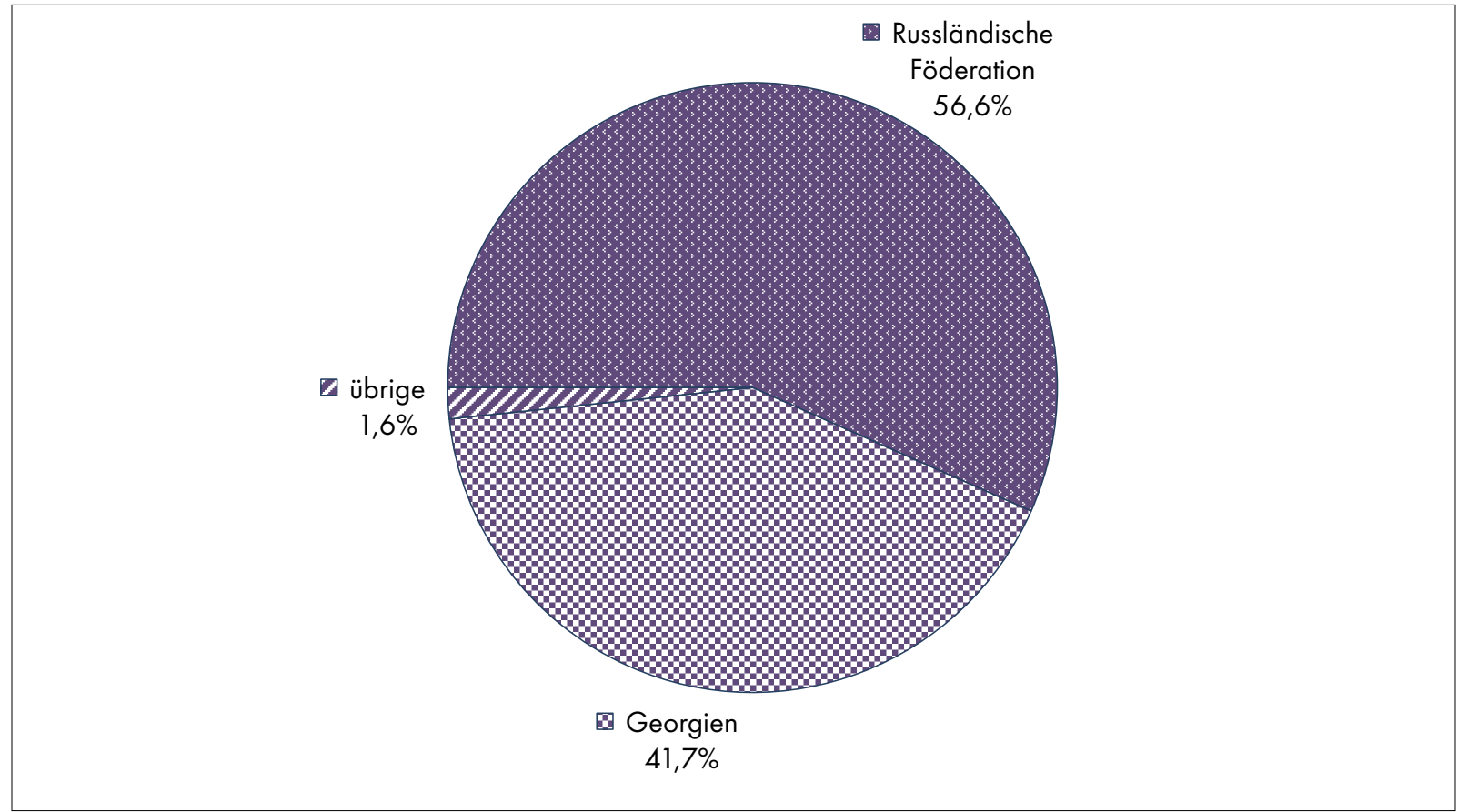

\begin{tabular}{|c|c|c|}
\hline & Summe & $\%$ \\
\hline insgesamt & 10.590 & 100 \\
\hline \multicolumn{3}{|c|}{ darunter am stärksten vertretene Nationen: } \\
\hline Russländische Föderation & 5.726 & 54,1 \\
\hline Georgien & 4.217 & 39,8 \\
\hline Armenien & 147 & 1,4 \\
\hline Vietnam & 67 & 0,6 \\
\hline Belarus & 37 & 0,3 \\
\hline Ukraine & 36 & 0,3 \\
\hline Nigeria & 23 & 0,2 \\
\hline Irak & 21 & 0,2 \\
\hline Pakistan & 19 & 0,2 \\
\hline Usbekistan & 19 & 0,2 \\
\hline Staatenlose & 19 & 0,2 \\
\hline
\end{tabular}

*Es handelt sich bei den Angaben um die Nationen, die zablenmäßig am stärksten vertreten sind.

Quelle: Urząd do Spraw Cudzoziemców [Amt für Ausländerangelegenheiten]: Dane liczbowe dotyczące postępowań prowadzonych wobec cudzoziemców w 2009 r. [Daten zu Verfahren gegenüber Ausländern im Jahr 2009], www.udsc.gov.pl (abgerufen am 29.01.2010). 


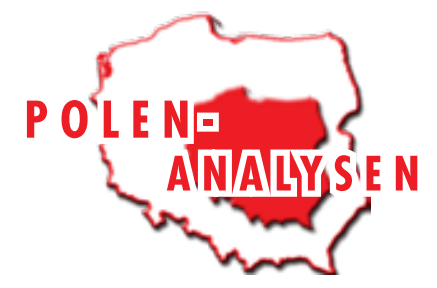

polen-analysen $64 / 10$

Entscheidungen in Verfahren zur Anerkennung des Flüchtlingsstatus 2009*

\begin{tabular}{|c|c|c|c|c|c|}
\hline & $\begin{array}{c}\text { Flüchtlingsstatus } \\
\text { gemäß Genfer } \\
\text { Konvention }\end{array}$ & subisidiärer Schutz & $\begin{array}{c}\text { tolerierter } \\
\text { Aufenthaltsstatus }\end{array}$ & $\begin{array}{c}\text { negative } \\
\text { Entscheidung }\end{array}$ & $\begin{array}{c}\text { Einstellung des } \\
\text { Verfahrens / kein } \\
\text { Verfahren }\end{array}$ \\
\hline Afghanistan & - & 3 & - & 4 & 4 \\
\hline Ägypten & - & - & - & 6 & 3 \\
\hline Albanien & - & - & - & 1 & - \\
\hline Algerien & - & - & - & 12 & 10 \\
\hline Angola & - & - & - & 1 & 1 \\
\hline Armenien & - & - & 6 & 58 & 71 \\
\hline Aserbaidschan & - & - & - & 5 & 13 \\
\hline Äthiopien & - & - & - & 2 & - \\
\hline Bangladesch & - & - & - & 14 & 4 \\
\hline Belarus & 20 & - & 1 & 25 & 25 \\
\hline Burundi & - & - & - & 1 & 2 \\
\hline China & - & - & - & 10 & 8 \\
\hline $\begin{array}{l}\text { Demokratische } \\
\text { Republik Kongo }\end{array}$ & - & - & - & 1 & - \\
\hline Gambia & - & - & - & 1 & - \\
\hline Georgien & - & - & - & 1.482 & 2.577 \\
\hline Ghana & - & - & - & 4 & 2 \\
\hline Guinea & - & - & - & 2 & 2 \\
\hline Indien & - & - & 1 & 17 & 11 \\
\hline Irak & 1 & 23 & - & 5 & 22 \\
\hline Iran & 4 & - & - & 1 & 2 \\
\hline Jordanien & - & - & - & 1 & - \\
\hline Kamerun & - & - & - & 7 & 7 \\
\hline Kasachstan & - & - & - & 4 & 9 \\
\hline Kenia & - & - & - & - & 2 \\
\hline Kirgisistan & - & - & - & 3 & 7 \\
\hline Komoren & - & - & - & - & 1 \\
\hline Kongo & - & - & - & 2 & 3 \\
\hline Kroatien & - & - & - & - & 1 \\
\hline Kuba & - & - & - & 3 & 1 \\
\hline Lettland & - & - & - & 2 & - \\
\hline Libanon & - & - & - & 2 & 4 \\
\hline Libyen & - & - & - & 3 & - \\
\hline Mali & - & - & - & - & 1 \\
\hline Marokko & - & - & - & 2 & 1 \\
\hline Mauretanien & - & - & - & 1 & - \\
\hline
\end{tabular}

(Fortsetzung auf nächster Seite) 


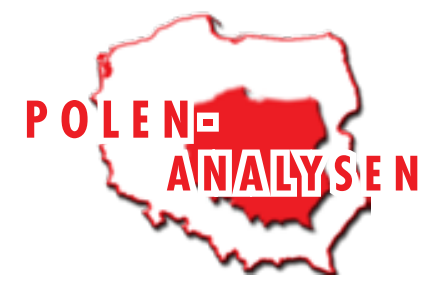

polen-analysen $64 / 10$

Entscheidungen in Verfahren zur Anerkennung des Flüchtlingsstatus 2009* (Fortsetzung)

\begin{tabular}{|c|c|c|c|c|c|}
\hline & $\begin{array}{c}\text { Flüchtlingsstatus } \\
\text { gemäß Genfer } \\
\text { Konvention }\end{array}$ & subisidiärer Schutz & $\begin{array}{c}\text { tolerierter } \\
\text { Aufenthaltsstatus }\end{array}$ & $\begin{array}{c}\text { negative } \\
\text { Entscheidung }\end{array}$ & $\begin{array}{c}\text { Einstellung des } \\
\text { Verfahrens / kein } \\
\text { Verfahren } \\
\end{array}$ \\
\hline $\begin{array}{l}\text { ehemalige jugo- } \\
\text { slawische Repu- } \\
\text { blik Mazedonien }\end{array}$ & - & - & - & - & 1 \\
\hline Moldawien & - & - & - & 8 & 1 \\
\hline Mongolei & - & - & 1 & 19 & 7 \\
\hline Nepal & - & 2 & - & - & 3 \\
\hline Nigeria & - & - & - & 13 & 10 \\
\hline Pakistan & 1 & - & 1 & 17 & 8 \\
\hline Philippinen & - & - & 1 & - & - \\
\hline Ruanda & - & - & - & 1 & - \\
\hline $\begin{array}{l}\text { Russländische } \\
\text { Föderation }\end{array}$ & 102 & 2.261 & 46 & 2.144 & 5.928 \\
\hline Sambia & - & - & - & 1 & - \\
\hline Senegal & - & 1 & - & - & - \\
\hline Serbien & - & - & - & - & 1 \\
\hline Sierra Leone & - & - & - & 2 & 2 \\
\hline Somalia & 2 & 6 & - & - & 2 \\
\hline Sri Lanka & - & 16 & - & - & 22 \\
\hline Sudan & - & 1 & - & - & - \\
\hline Syrien & - & - & - & 12 & 6 \\
\hline Tadschikistan & - & - & - & 2 & - \\
\hline Togo & - & - & - & 8 & 2 \\
\hline Tunesien & - & - & - & 2 & 5 \\
\hline Türkei & - & - & - & 19 & 7 \\
\hline Uganda & - & - & - & 1 & - \\
\hline Ukraine & - & - & 4 & 29 & 14 \\
\hline Usbekistan & - & - & - & 9 & 23 \\
\hline Venezuela & - & - & - & 1 & - \\
\hline Vietnam & 1 & - & 3 & 65 & 8 \\
\hline $\begin{array}{l}\text { Westbank und } \\
\text { Gazastreifen }\end{array}$ & - & 3 & - & 3 & 3 \\
\hline Staatenlos & - & 1 & 1 & 10 & 14 \\
\hline
\end{tabular}

*ausgegeben vom Leiter der Amtes für Ausländerangelegenheiten [Urząd do Spraw Cudzoziemców] in der Zeit vom 1.01.-31.12.2009

Quelle: Urząd do Spraw Cudzoziemców [Amt für Ausländerangelegenheiten]: Dane liczbowe dotyczące postępowań prowadzonych wobec cudzoziemców w 2009 r. [Daten zu Verfahren gegenüber Ausländern im Jahr 2009], www.udsc.gov.pl (abgerufen am 29.01.2010). 


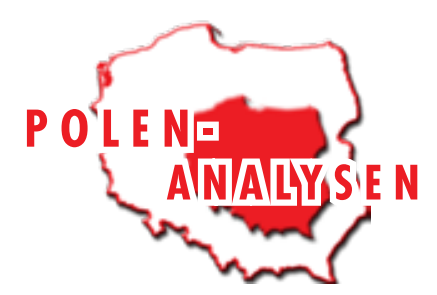

Chronik

\section{Vom 19. Januar bis zum 01. Februar 2010}

\begin{tabular}{|c|c|}
\hline 19.01.2010 & $\begin{array}{l}\text { Der Vorsitzende der Partei Freiheit und Rechtsstaatlichkeit (Wolność i Praworządność - WiP), Janusz Korwin- } \\
\text { Mikke, tritt als Kandidat der WiP und der Union für Realpolitik (Unia Polityki Realnej - UPR) für die Prä- } \\
\text { sidentschaftswahl im Herbst } 2010 \text { an. }\end{array}$ \\
\hline 20.01 .2010 & $\begin{array}{l}\text { Verteidigungsminister Bogdan Klich gibt bekannt, dass die im Rahmen des US-amerikanischen Raketenabwehr- } \\
\text { systems für Polen vorgesehenen Patriot-Raketen sowie US-Soldaten im April in Mohrungen (Morag)/Masuren } \\
\text { stationiert werden. Klich versichert, dass die Nähe des Ortes zur russischen Grenze (Oblast Kaliningrad) keine } \\
\text { Bedeutung für die Entscheidung gehabt habe. Die Raketen werden in Polen vorübergehend stationiert. }\end{array}$ \\
\hline 21.10 .2010 & $\begin{array}{l}\text { Staatspräsident Lech Kaczyński wird in Prag vom tschechischen Staatspräsidenten Vacláv Klaus die höchste } \\
\text { staatliche Auszeichnung, der Orden des Weißen Löwen, verliehen. Auf einer Pressekonferenz sprechen sich } \\
\text { beide Staatsoberhäupter dafür aus, dass die Europäische Union nach Inkrafttreten des Lissabonner Vertrags kein } \\
\text { "Superstaat« werde dürfe, sondern sich als starkes Staatenbündnis verstehen müsse. }\end{array}$ \\
\hline 22.01 .2010 & $\begin{array}{l}\text { Nach Prognosen des Ministeriums für Arbeit und Sozialpolitik wird die Arbeitslosigkeit im Januar saisonbedingt } \\
\text { auf über } 12 \% \text { ansteigen, so die stellvertretende Ministerin Czesława Ostrowska. Bis zum Jahresende werde ein } \\
\text { Anstieg auf 12,8\% angenommen, verursacht durch das demographische Hoch in den 1980er Jahren. }\end{array}$ \\
\hline 23.01 .2010 & $\begin{array}{l}\text { Der Staatssekretär für Auswärtige Angelegenheiten beim Staatspräsidenten, Mariusz Handzlik, äußert sich } \\
\text { konsterniert über die Ankündigung des scheidenden ukrainischen Staatspräsidenten Viktor Juschtschenko, dem } \\
\text { Anführer der Organisation Ukrainischer Nationalisten (UPA), Stepan Bandera, posthum den Titel »Held der } \\
\text { Ukraine« zuzuerkennen. Bandera ist - nicht nur - in Polen eine kontroverse Persönlichkeit, da ihm Kollaboration } \\
\text { mit dem Dritten Reich während des Zweiten Weltkriegs und den ihm unterstehenden ukrainischen Kampfver- } \\
\text { bänden massenhafte ethnische Säuberungen vorgeworfen werden. Handzlik ruft die Ukraine auf, in historischen } \\
\text { Angelegenheiten mehr ethisches und politisches Feingefühl walten zu lassen. }\end{array}$ \\
\hline 25.01 .2010 & $\begin{array}{l}\text { Der Vorsitzende der Unabhängigen Selbstverwalteten Gewerkschaft "Solidarność" (Niezależny Samorządny } \\
\text { Związek Zawodowy NSZZ »Solidarność), Janusz Śniadek, und der Chef der Gesamtpolnischen Allianz der } \\
\text { Gewerkschaften (Ogólnopolskie Porozumienie Związków Zawodowych - OPZZ), Jan Guz, drängen darauf, } \\
\text { noch im Januar Gespräche mit der Regierung und Arbeitgebervertretern über eine Erhöhung des Mindestlohns } \\
\text { zu führen, wie es Ministerpräsident Donald Tusk im Mai letzten Jahres in Aussicht gestellt hatte. Der derzeitige } \\
\text { Mindestlohn beträgt } 1.317 \text { Zloty, das sind } 42 \% \text { des Landesdurchschnitts. Die Gewerkschaften fordern eine } \\
\text { Anhebung auf } 50 \% \text {. }\end{array}$ \\
\hline 26.01 & $\begin{array}{l}\text { Der Ständige Präsident des Europäischen Rates, Herman van Rompuy, reist zu Gesprächen mit Staatspräsident } \\
\text { Lech Kaczyński und Ministerpräsident Donald Tusk nach Warschau. Thematisiert werden u. a. die wirtschaftliche } \\
\text { Strategie der Europäischen Union in der globalen Krise, die auf dem EU-Sondergipfel im Februar bestimmt } \\
\text { werden soll, und die Konsequenzen aus dem Weltklimagipfel in Kopenhagen im Dezember 2009. Tusk erklärt, } \\
\text { van Rompuy und er würden darin übereinstimmen, dass man bei der Bekämpfung der Wirtschaftskrise auf } \\
\text { traditionelle Werte wie maximale Verantwortungsübernahme, Sparsamkeit, den Glauben an die freie Marktwirt- } \\
\text { schaft und das Privateigentum und die Missbilligung nationaler Egoismen sowie die Missbilligung von Protektio- } \\
\text { nismus setzen wolle. Kaczyński hebt hervor, er habe mit dem Präsidenten über die Beziehungen zwischen dem neu } \\
\text { geschaffenen Amt des Ständigen Präsidenten und der jeweiligen nationalen EU-Ratspräsidentschaft gesprochen. } \\
\text { Van Rompuys Aufenthalt in Warschau ist der erste in seiner neuen Funktion, die mit dem EU-Reformvertrag von } \\
\text { Lissabon neu eingerichtet worden ist. Polen wird im zweiten Halbjahr } 2011 \text { den EU-Ratsvorsitz übernehmen. }\end{array}$ \\
\hline 26.01 .2010 & $\begin{array}{l}\text { Aus Anlass der Gedenkveranstaltungen zum 65. Jahrestag der Befreiung des ehemaligen NS-Konzentrations- } \\
\text { lagers Auschwitz treffen sich in Warschau Staatspräsident Lech Kaczyński und Ministerpräsident Donald Tusk } \\
\text { mit dem israelischen Ministerpräsidenten Benjamin Netanjahu. Kaczyński bekräftigt, dass sich Polen für die } \\
\text { Zwei-Staaten-Lösung für Israel und Palästina ausspricht. Tusk stellt die Einrichtung von polnisch-israelischen } \\
\text { Regierungskonsultationen in Aussicht. }\end{array}$ \\
\hline 27.01 .2010 & $\begin{array}{l}\text { Im ehemaligen NS-Konzentrationslager Auschwitz findet die Hauptgedenkveranstaltung zum 65. Jahrestag der } \\
\text { Befreiung des Lagers durch die Rote Armee statt, an der ehemalige Häftlinge und Politiker, darunter Staatsprä- } \\
\text { sident Lech Kaczyński, Ministerpräsident Donald Tusk, der ehemalige Auschwitz-Häftling und Staatssekretär } \\
\text { für Auswärtige Angelegenheiten beim Ministerpräsidenten, Władysław Bartoszewski, der israelische Minister- } \\
\text { präsident Benjamin Netanjahu, der Präsident des Europäischen Parlaments, Jerzy Buzek, die Staatsministerin } \\
\text { und Koordinatorin für die deutsch-polnischen Beziehungen, Cornelia Pieper, und der russische Bildungsminister } \\
\text { Andrej Fursenko teilnehmen. }\end{array}$ \\
\hline
\end{tabular}




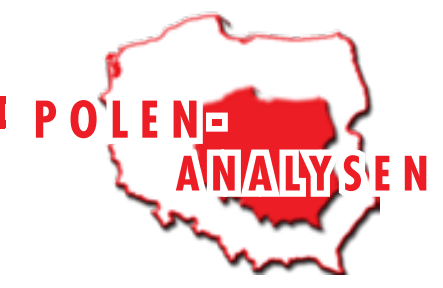

\begin{tabular}{|l|l|}
\hline 28.01.2010 & $\begin{array}{l}\text { Ministerpräsident Donald Tusk gibt seine Entscheidung bekannt, nicht als Kandidat für die Präsidentschafts- } \\
\text { wahl anzutreten. Das Land brauche während zweier Wahlkampagnen (für das Amt des Staatspräsidenten und } \\
\text { die Selbstverwaltungswahlen) eine stabile Regierung. }\end{array}$ \\
\hline 29.01.2010 & $\begin{array}{l}\text { Ministerpräsident Donald Tusk stellt gemeinsam mit Finanzminister Jacek Rostowski den »Plan zur Kon- } \\
\text { solidierung und Entwicklung der Finanzen 2010-2011« vor. Dieser sieht u. a. eine Senkung des Haushaltsdefizits } \\
\text { von gegenwärtig 7\% des Bruttoinlandsprodukts (BIP) auf 3\% vor, die Aufhebung von Privilegien für die »uni- } \\
\text { formierten Berufe« und eine Gruppe von Landwirten bei Rentenbeiträgen und -zahlungen, die Verschärfung des } \\
\text { Steuersystems für Ärzte, Juristen und Unternehmer und die Privatisierung von Firmen. }\end{array}$ \\
\hline 30.01.2010 & $\begin{array}{l}\text { Abgeordnete von Recht und Gerechtigkeit (Prawo i Sprawiedliwość - PiS) kritisieren auf einer Pressekonferenz } \\
\text { den am Vortag vorgestellten Plan von Ministerpräsident Donald Tusk zur Reform der öffentlichen Finanzen als } \\
\text { unkonkret. }\end{array}$ \\
\hline $\begin{array}{l}\text { Nach Angaben der Tageszeitung } \\
\text { noujście) ein Schreiben an das Bundesamt für Seeschifffahrt und Hydrographie (BSH) in Hamburg gerichtet, } \\
\text { in dem Einspruch gegen die vom BSH erteilte Erlaubnis angekündigt wird, einen Teil der sogenannten Ostsee- } \\
\text { pipeline in den deutschen Hoheitsgewässern vor Swinemünde in der vorgesehenen Tiefe zu verlegen. Dies würde } \\
\text { den Schiffsverkehr in den Hafen beeinträchtigen, da die Gasleitung die Einfahrt sowie die Fahrt in Hafennähe } \\
\text { für Schiffe ab einem Tiefgang von mehr als 13,2 m unmöglich machen würde. }\end{array}$ \\
$\begin{array}{l}\text { Im Rahmen des Weimarer Dreiecks trifft sich in Warschau der Staatssekretär für Europäische Angelegenheiten im } \\
\text { Außenministerium, Mikołaj Dowgielewicz, mit seinen deutschen und französischen Amtskollegen, Staatsminister } \\
\text { Werner Hoyer und Staatssekretär Pierre Lellouche. Thematisiert werden eine gemeinsame Wirtschaftsstrategie } \\
\text { für Europa, die Fortsetzung der Klimaverhandlungen nach dem Weltklimagipfel in Kopenhagen im Dezember } \\
\text { 2009 und die Energiesicherheit in Europa. Weitere Themen sind das Programm der Östlichen Partnerschaft der } \\
\text { EU, das Verhältnis der Union zur Ukraine und die europäische Sicherheitspolitik. }\end{array}$ \\
\hline 01.02 .2010
\end{tabular}




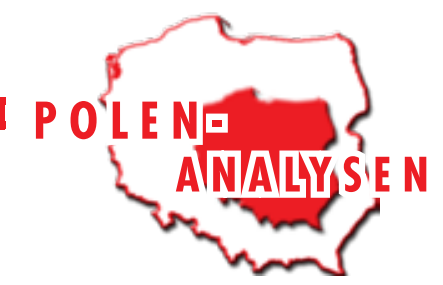

\section{Lesehinweis}

\section{Jahrbuch Polen 2010 Migration}

Herausgegeben vom Deutschen Polen-Institut Darmstadt ca. 220 Seiten,

Preis $€ 11,80$

(€ 9 im Abonnement)

ISBN 978-3-447-06189-6

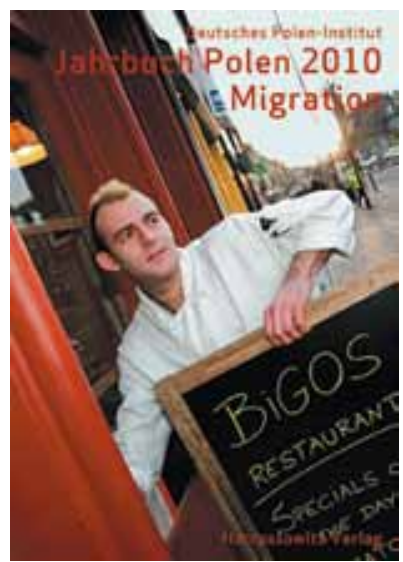

INHALT

"Nach 2004 wurde Deutschland als Hauptzielland polnischer Migration von Großbritannien und Irland abgelöst. Tausende von Menschen, die die saisonale oder vorübergehende Migration in den unsicheren Zeiten der polnischen Transformation und des holprigen Weges zum Kapitalismus zu ihrer Überlebensstrategie gemacht hatten, wählten ebenso wie junge Hochschulabsolventen, die ihre erste Arbeitsstelle suchten, die Britischen Inseln."

(Michał Garapich)

„Die unmittelbaren Nutznießer der Migration sind mehrheitlich diejenigen polnischen Migranten, die eine Möglichkeit gefunden haben, legal im Ausland zu arbeiten und ein Einkommen zu beziehen. Da die Mehrzahl von ihnen jedoch einer Tätigkeit unter der eigenen Qualifikation und dem eigenen Bildungsniveau nachgeht, liegt hier sofort die Schlussfolgerung nahe, dass in absehbarer Zeit ein Teil von ihnen zu den größten Verlierern dieses Prozesses zählen wird.» (Krystyna Iglicka)

"Ich vermute, dass die Polen sich in deutschen Städten ansiedeln werden. Renommierte Wissenschaftszentren werden Spezialisten an sich ziehen, ähnlich wie die großen Konzerne und Banken. Polnisches Bürgertum wird in Hamburg, Frankfurt, München und Düsseldorf auftauchen - sofern es nicht schon da ist. Die ältere Generation der polnischen Emigranten von vor 25 Jahren wird sie anschauen und sich verwundert die Augen reiben. In ihrer Generation war ein Manager mit polnischem Pass etwas Besonderes, aber bald wird er zum Alltagsbild gehören.»

(Bartosz Wieliński)

(c) Otto Harrassowitz GmbH \& Co. KG,

Wiesbaden 2010

www.deutsches-polen-institut.de

Gefördert von der Kulturabteilung des Auswärtigen Amtes, Berlin
Basil Kerski:

Bartosz Wieliński: Jetzt kommen die Polen mit den

dicken Portemonnaies
Germanys next pole position. Elf

Uwe Rada:

Rainer Mende:

Michał P. Garapich:

Vorwort

Essays

Hybride Identitäten. Migrationen aus Polen - Geschichte und Gegenwart Bemerkungen zum Wandel des Bildes der Deutschen von ihren Polen Grenzgänger, Wurstmenschen und Mythenzersetzer. Ein kleines Porträt polnischsprachiger Literatur aus Deutschland

Die Nomaden Europas - Polnische Migranten in der Risikogesellschaft

Krystyna Iglicka: Kosten- und Nutzenbilanz der neuesten Arbeitsmigrationswelle aus Polen

Magdalena Nowicka: "Hängen geblieben«. Bildungsmigranten aus Polen und ihre Zukunftsperspektiven in Deutschland

Anna Kicinger: $\quad$ Einwanderungspolitik in einem Auswandererland Reportage

Katarzyna Kulczycka: To go or not to go. Nach Schottland sollte er nur für ein Jahr gehen Analyse

Elmar Hönekopp: Polen auf dem deutschen Arbeitsmarkt: Chancen für Fachkräfte, Risiken für Niedrigqualifizierte Literatur

Jacek Kaczmarski: Unsere Klasse

Janusz Głowacki: Amerika

Manuela Gretkowska: Teresa Torańska: Janusz Rudnicki: Paulina Schulz: Andrzej Bobkowski: Stanisław Barańczak: My zdies' emigranty Wir sind da. Abschiede '68 Hamburger Dreierpack Literatur als Heimat In der Etappe

Gedichte Mein Jahr

Paweł Huelle:

Was ist Vergangenheit? Mein Jahr 2009

Vorbestellungen bei:

Harrassowitz Verlag 65174 Wiesbaden

Fax: 0611 - 530-999

eMail: rgietz@harrassowitz.de

www.harrassowitz-verlag.de 


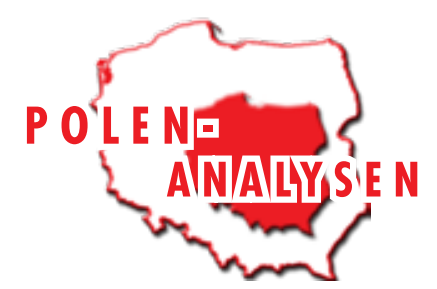

Über die Polen-Analysen

Die Polen-Analysen erscheinen zweimal monatlich als E-Mail-Dienst. Sie werden gemeinsam vom Deutschen PolenInstitut Darmstadt, der Bremer Forschungsstelle Osteuropa und der Deutschen Gesellschaft für Osteuropakunde herausgegeben.

Ein Archiv der Polen-Analysen finden Sie im Internet unter www.laender-analysen.de/polen

Kostenloses Abonnement unter http://www.deutsches-polen-institut.de/Newsletter/subscribe.php

\section{Deutsches Polen-Institut Darmstadt}

Das Deutsche Polen-Institut Darmstadt (DPI) ist ein Forschungs-, Informations-, und Veranstaltungszentrum für polnische Kultur, Geschichte, Politik, Gesellschaft und die deutsch-polnischen Beziehungen, die sich im Kontext der europäischen Integration entwickeln. Das seit März 1980 aktive und bis 1997 von Gründungsdirektor Karl Dedecius geleitete Institut ist eine Gemeinschaftsgründung der Stadt Darmstadt, der Länder Hessen und Rheinland-Pfalz sowie des Bundes. Seit 1987 ist die Trägerschaft auf die Kultusminister der Länder ausgedehnt. Einen wesentlichen Beitrag zur Verwirklichung der Institutsziele leisten private Stiftungen. Das DPI hat satzungsgemäß die Aufgabe, durch seine Arbeit zur Vertiefung der gegenseitigen Kenntnisse des kulturellen, geistigen und gesellschaftlichen Lebens von Polen und Deutschen beizutragen.

Ziel der Vermittlertätigkeit des DPI ist es, „die zu interessieren, auf die es politisch, wirtschaftlich, gesellschaftlich und kulturell im deutsch-polnischen Verhältnis ankommt« (Leitlinien 1997). Es geht um die Entscheider und Multiplikatoren in Politik, Kultur, Bildung, Verwaltung, Medien und Wirtschaft und, wesentlich stärker ausgeprägt als bisher, um das Hineinwirken in Wissenschaft, Forschung und Bildung.

Derzeit bemüht sich das DPI in Kooperation mit den verstreuten Orten wissenschaftlicher Polen-Kompetenz an deutschen Hochschulen und Forschungsinstituten verstärkt darum, ausgehend von einer Bestandsaufnahme deutscher Polen-Forschung Ort wissenschaftlicher Forschung und verbindendes, vernetzendes und kooperierendes Zentrum zu werden. Ausgangspunkt der Neuausrichtung ist die kaum mehr kontrollierbare Dynamik des Rückbaus der Ressourcen der wissenschaftlichen Polen-Kompetenz in den unterschiedlichen Disziplinen. Mit der über 55.000 Bände zählenden multidisziplinären Fachbibliothek für Polen mit einer einzigartigen Sammlung polnischer Literatur in der Originalsprache und in deutscher Übersetzung ist das DPI bereits ein geschätzter Ort der Recherche und des wissenschaftlichen Arbeitens. (www.deutsches-polen-institut.de)

\section{Forschungsstelle Osteuropa an der Universität Bremen}

1982 gegründet, widmet sich die Forschungsstelle Osteuropa an der Universität Bremen kulturellen und gesellschaftlichen Entwicklungen der Länder Ost- und Ostmitteleuropas in Zeitgeschichte und Gegenwart. Die Forschungsstelle besitzt in ihrem Archiv eine einzigartige Sammlung alternativer Kulturgüter und unabhängiger Texte aus den ehemaligen sozialistischen Ländern. Darunter befindet sich auch eine umfangreiche Sammlung des "Zweiten Umlaufs", die das Schrifttum und Dokumente unabhängiger Initiativen und gesellschaftlicher Gruppen in Polen aus der Zeit von 1976 bis zum Umbruch umfasst. Neben ausführlicher individueller Forschung zu Dissens und Gesellschaft im Sozialismus, leitet die Forschungsstelle seit Januar 2007 ein gemeinsames Projekt mit einem Verbund von internationalen Forschungsinstituten zum Thema "Das andere Osteuropa - die 1960er bis 1980er Jahre, Dissens in Politik und Gesellschaft, Alternativen in der Kultur. Beiträge zu einer vergleichenden Zeitgeschichte«, welches von der VolkswagenStiftung finanziert wird.

Im Bereich der post-sozialistischen Gesellschaften sind in den letzten Jahren umfangreiche Forschungsprojekte durchgeführt worden, deren Schwerpunkte auf politischen Entscheidungsprozessen, Wirtschaftskultur und der EU-Osterweiterung lagen. Eine der Hauptaufgaben der Forschungsstelle ist die Information der interessierten Öffentlichkeit. Dazu gehören unter anderem regelmäßige E-Mail-Informationsdienste mit fast 15.000 Abonnenten in Politik, Wirtschaft und den Medien.

Mit ihrer in Deutschland einzigartigen Sammlung von Publikationen zu Osteuropa ist die Forschungsstelle eine Anlaufstelle sowohl für Wissenschaftler als auch für die interessierte Öffentlichkeit. In der Bibliothek sind derzeit neben anderen breit angelegten Beständen allein aus Polen ca. 300 laufende Periodika zugänglich. Die Bestände werden in Datenbanken systematisch erfasst. (www.forschungsstelle.uni-bremen.de)

Die Meinungen, die in den Polen-Analysen geäußert werden, geben ausschließlich die Auffassung der Autoren wieder. Abdruck und sonstige publizistische Nutzung sind nach Rücksprache mit der Redaktion gestattet.

Redaktion: Prof. Dr. Dieter Bingen (Darmstadt), Silke Plate, M.A. (Bremen) Technische Gestaltung: Matthias Neumann

Polen-Analysen-Layout: Cengiz Kibaroglu, Matthias Neumann

Die Polen-Analysen werden im Rahmen der Datenbank World Affairs Online (WAO) ausgewertet und sind im Portal IREON www.ireon-portal.de recherchierbar.

ISSN 1863-9712 @ 2010 by Deutsches Polen-Institut Darmstadt und Forschungsstelle Osteuropa, Bremen

Kontakt: Dr. Andrzej Kaluza, Presse- und Öffentlichkeitsarbeit, Deutsches Polen-Institut, Mathildenhöhweg 2,

D-64287 Darmstadt, Tel.: 06151/4985-13, Fax: 06151/4985-10, E-Mail: polen-analysen@dpi-da.de, Internet: www.laender-analysen.de/polen 